PNNL-11124

UC-810

Project Technical Information

Initial Evaluation of Two Organic Resins and Their lon Exchange Column Performance for the Recovery of Cesium from Hanford Alkaline Wastes
L. A. Bray
C. D. Carlson
K. J. Carson
J. R. DesChane
R. J. Elovich
D. E. Kurath

April 1996

Prepared for

the U.S. Department of Energy

under Contract DE-AC06-76RLO 1830

Pacific Northwest National Laboratory

Richland, Washington 99352 
PNNL-11124

UC-810

\title{
Initial Evaluation of Two Organic Resins and their Ion Exchange Column Performance for the Recovery of Cesium from Hanford Alkaline Wastes
}

\author{
LA Bray \\ CD Carlson \\ KJ Carson \\ JR DesChane \\ RJ Elovich \\ DE Kurath
}

April 1996

\section{Prepared for}

the U.S. Department of Energy

under Contract DE-AC06-76RLO 1830

Pacific Northwest National Laboratory

Richland, Washington 99352 


\title{
DISCLAIMER
}

This report was prepared as an account of work sponsored by an agency of the United States Government. Neither the United States Government nor any agency thereof, nor Battelle Memorial Institute, nor any of their employees, makes any warranty, express or implied, or assumes any legal liability or responsibility for the accuracy, completeness, or.usefulness of any information, apparatus, product, or process disclosed, or represents that its use would not infringe privately owned rights. Reierence herein to any specific commercial product, process, or service by trade name, trademark, manufacturer, or othenvise dues not necessarily constitute or imply its endorsement, recommendation, or favoring by the United States Government or any agency thereof, or Bartelle Memorial Institute. The views and opinions of authors expressed herein do not necessarily state or reflect those of the United States Government or any agency thereof.

\section{PACIFIC NORTHWEST NATIONAL LABORATORY operated by BATTELLE for the \\ UNITED STATES DEPARTMENT OF ENERGY under Contract DE-ACO6-76RLO 1830}

\author{
Prinled in the United States of America \\ Available to DOE and DOE contractors from the \\ Office oi Scientiñ and Techniral Information. P.O. Box 62, Oak Ridge, TN 37839; \\ prices available from (615) 576-8401.
}

Available to the public from the National Technical information Service, U.S. Department of Commerce, 5285 Port Royal Rd., Springfield, VA 22161 
At the request of Westinghouse Hanford $\mathrm{Co}_{\mathrm{O}}$ (WHC), the Pacific Northwest Laboratory (PNL) has studied several ion exchange materials for the recovery of cesium from Hanford waste tanks. The WHC program was divided into two main tasks, 1) to obtain equilibrium data for cesium ion exchange (initiated in FY92), and 2) to evaluate ion exchange column performance. The subject of this letter report is the initial evaluation of the ion exchange performance for CS-100 (an organic resin produced by Rohm and Haas) and BIB-DJ (a new resorcinol-formaldehyde organic resin, first prepared by Dr. Jane Bibler [Westinghouse Savannah River Co. (WSRC)] and produced by Boulder Scientific Co.

The following conclusions were developed after completion of the initial ion exchange column study:

- Recovery of cesium from Hanford highly alkaline wastes can be achieved by using an organic ion exchange resin (CS-100 or BIB-DJ). The cesium can be recovered from the exchangers using acid elution.

- $\quad$ CS-100 resin extracts cesium and can be acid stripped to decontamination levels suitable for resin reuse. Acid stripping results for BIB-DJ do not show that the resin is reusable. Additional stripping test conditions will be evaluated.

- Batch cesium distribution data (Bray et al, 1992) for both CS-100 and BIB-DJ accurately projected the ion exchange capacity of the exchangers.

- The capacity of the CS-10Q resin using $5 \mathrm{M} \mathrm{Na}{ }^{+} \mathrm{NCAW}$ feed with a cesium concentration of $5 \mathrm{E}-4 \mathrm{M} \mathrm{Cs}^{+}$was $30 \mathrm{cV}$ or $\overline{2} \mathrm{~g}$ of $\mathrm{Cs} / \mathrm{L}$ of exchanger. The capacity of BIB-DJ was $190 \mathrm{cv}$ or $12.6 \mathrm{~g}$ of $\mathrm{Cs} / \mathrm{L}$ of exchanger, providing a cesium capacity factor of 6.3 greater than for CS-100.

- Multiple column tests (three in series) provide valuable flow rate data, indicating that the data provided by the laboratory $200 \mathrm{~mL}$ ion exchange columns $(2.54 \mathrm{~cm}$ dia.) can be used to directly scale-up to large-scale processing columns. 
- The BIB-DJ organic resin is outstanding in its loading kinetics as compared to the CS-100. The volume of feed through the column at which the initial detectable cesium breakthrough $\left(\mathrm{C} / \mathrm{CO}_{0}=0.0001\right)$ was noted varied for the CS-100 resin from 2.5 to $7 \mathrm{cv}$ as the flow rate was varied from 9 to $3 \mathrm{cv} / \mathrm{hr}$. Under similar conditions for the BIB-DJ resin, the detectable cesium breakthrough varied from $100 \mathrm{cv}$ to $160 \mathrm{cv}$.

- Formic ( $\mathrm{HCOOH}$ ) and nitric $\left(\mathrm{HNO}_{3}\right)$ acids were used to elute the cesium from the loaded ion exchange columns. Both $0.1 \mathrm{M} \mathrm{HNO}_{3}$ and $1 \mathrm{M} \mathrm{HCOOH}$ were effective in the removal of cesium from the CS-100 resin. The volume of acid consumed doubled when the flow rate was increased from $1 \mathrm{cv} / \mathrm{hr}$ to 6 $\mathrm{cv} / \mathrm{hr}$. No effect on reducing the eluant volume was noted when the temperature was increased from $25^{\circ} \mathrm{C}$ to $40^{\circ} \mathrm{C}$. Formic acid was more effective in the removal of cesium from BIB-DJ resin. Using $25 \mathrm{cv}$ of acid, $\sim 40 \%$ of the cesium was recovered using $0.1 \mathrm{M} \mathrm{HNO}_{3}$ and $\sim 97 \%$ using 1 N $\mathrm{HCOOH}$. 


\section{ACKNOWLEDGMENTS}

Pacific Northwest Laboratory (PNL) is collaborating with universities, national laboratories, and industry to develop ion exchange materials for the pretreatment of nuclear wastes stored at Hanford. The authors would like to acknowledge the contributions to this effort of Mr. Ronald M. Orme, Westinghouse Hanford Company; Dr. Jane Bibler, Westinghouse Savannah River Laboratory; and Mr. John Burningham, Boulder Scientific Co. 


\section{CONTENTS}

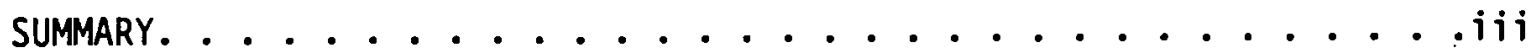

ACKNOWLEDGMENTS. ..................... . . . .

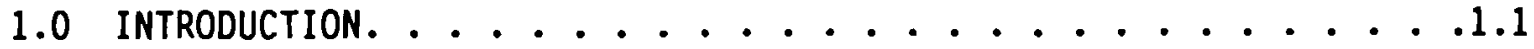

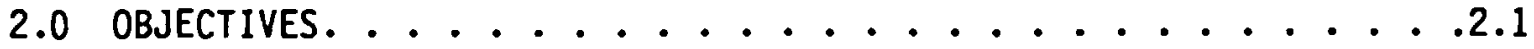

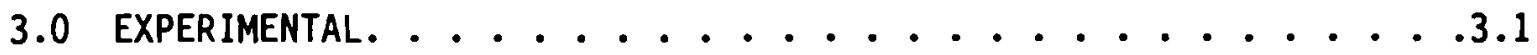

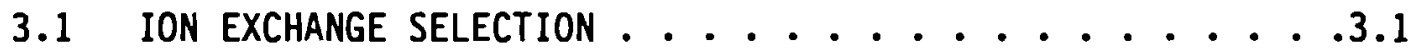

3.2 VARIABLES TO BE. CONSIDERED TO OBTAIN

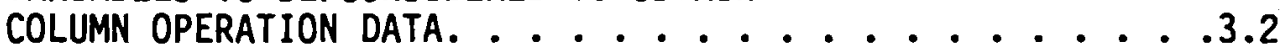

3.3 EQUIPMENT DESCRIPTION. . . . . . . . . . . . . . . .

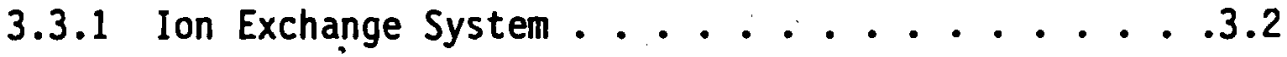

3.3.2 Single Column Configuration . . . . . . . . 3.3

3.3.3 Multi-Column Configuration. . . . . . . . . 3.3

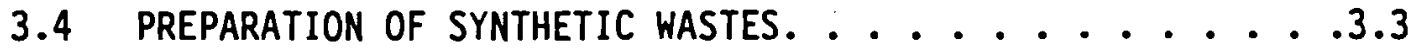

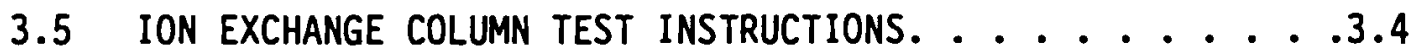

3.5.1 Candidate Ion Exchanger Preparation ...... . 3.4

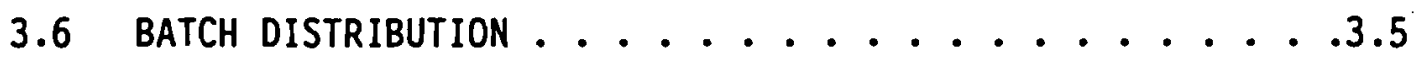

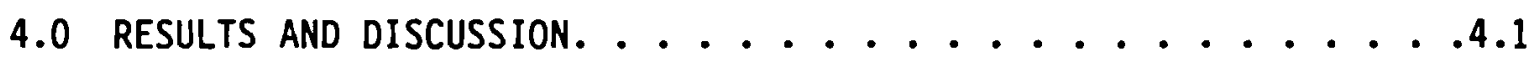

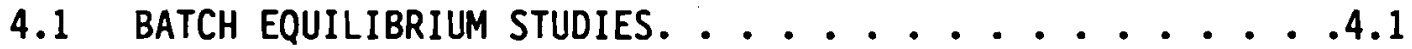

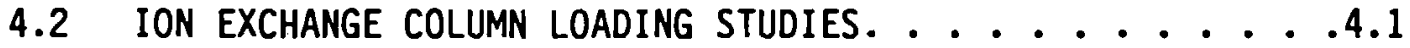

4.2 .1 CS-100 Studies. . . . . . . . . . . 4.5

4.2.2 NaOH Washed BIB-DJ Studies. . . . . . . . 4.12

4.2.3 Batch Distribution Studies to Determine BIB-DJ

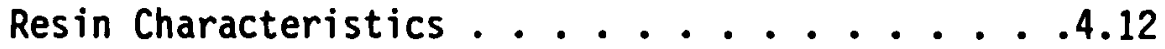

4.2.4 BIB-DJ Studies - No Pretreatment. . . . . . .4.14

4.3 ION EXCHANGE COLUMN ELUTION STUDIES. .............. . . . .

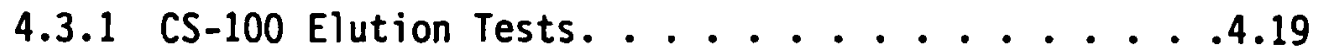

4.3.2 BIB-DJ Elution Tests. .............. . . . .

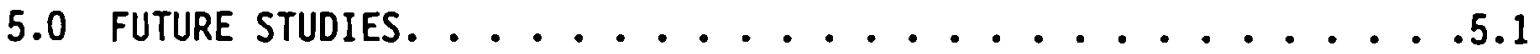

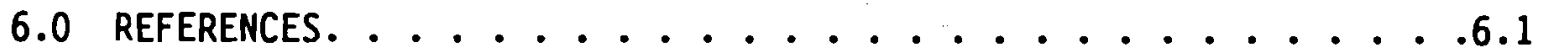




\section{FIGURES}

4.1 Batch Distribution Studies - CS-100 and NCAW. . . . . . . 4.2

4.2 Batch Distribution Studies - BIB-DJ and NCAW. . . . . . . 4.3

4.3 Comparison Between IE-96, CS-100, BIB-DJ and TAM-70 at an Equilibrium $\mathrm{Na} / \mathrm{Cs}$ Mole Ratio of $10^{4}$. . . . . . . 4.4

4.4 CS-100 Cesium Loading Test - Column A; 1,200 mL/hr. . . . . 4.6

4.5 CS-100 Cesium Loading Test - Columns I, J, K; $600 \mathrm{~mL} / \mathrm{hr}$. . . . 4.7

4.6 CS-100 Cesium Loading Test - Columns C, D, E; $1,200 \mathrm{~mL} / \mathrm{hr}$. . 4.8

4.7 CS-100 Cesium Loading Test - Columns 0, P, Q; 1,800 mL/hr . . 4.9

4.8 CS-100 Cesium Loading Results - Cs Breakthrough as a Function of Flow Rate ............... . 4.10

4.9 CS-100 Cesium Loading Results - Cs Breakthrough as a Function of Flow Velocity ................ 4.11

4.10 BIB-DJ Cesium Loading Test - Column B; 1,200 mL/hr. . . . . . 4.13

4.11 BIB-DJ Cesium Loading Test - Columns R, S, T; $1,800 \mathrm{~mL} / \mathrm{hr}$. . 4.16

4.12 BIB-DJ Cesium Loading Results - Cs Breakthrough as a

function of Flow Rate ............... 4.18

4.13 CS-100 Elution as a Function of Acid Concentration $-1 \mathrm{cv} / \mathrm{hr}, 25^{\circ} \mathrm{C}$..................... . . .

$4.14 \mathrm{CS}-100$ Elution with $0.05 \mathrm{M} \mathrm{HNO}_{3}$ as a Function of $\mathrm{pH}$. . . . . .4.22

$4.15 \mathrm{CS}-100$ Elution with $1 \mathrm{M} \mathrm{HCOOH}$ as a Function of $\mathrm{pH}$. . . . . .4.23

4.16 CS-100 Elution as a Function of Flow Rate - 1 to $6 \mathrm{cv} / \mathrm{hr}, 25^{\circ} \mathrm{C}$............... . . . . . . . . .

4.17 CS-100 Elution as a Function of Temperature $-6 \mathrm{cv} / \mathrm{hr}, 25^{\circ} \mathrm{C}-40^{\circ} \mathrm{C} \ldots \ldots . . . . . . . .4 .25$

4.18 BIB-DJ Elution as a Function of Acid Concentration - $1 \mathrm{cv} / \mathrm{hr}, 25^{\circ} \mathrm{C}$. . . . . . . . . . . 4.26

4.19 Elution of CS-100 and BIB-DJ Resins with $0.1 \mathrm{M} \mathrm{HNO}_{3}-1 \mathrm{cv} / \mathrm{hr}, 25^{\circ} \mathrm{C}$. . . . . . . . . . . . . .4.27

4.20 Elution of CS-100 and BIB-DJ Resins with IN Formic Acid - $1 \mathrm{cv} / \mathrm{hr}, 25^{\circ} \mathrm{C}$. . . . . . . . . . .4.28 


\section{TABLES}

TABLE 3.1 Neutralized Current Acid Waste - Synthetic

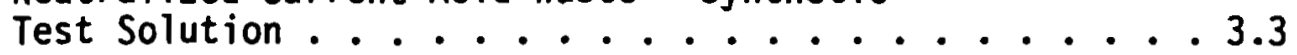

TABLE 4.1 Cesium Loading Experiments. ........... 4.1

TABLE 4.2 Cesium Batch Distribution Studies for BIB-DJ. . . . . 4.14

TABLE 4.3. Cesium Batch Distribution Studies for BIB-DJ,

55 gallon Drum. .................. 4.15

TABLE 4.4 Cesium Elution Experiments. ........... 4.17 


\subsection{INTRODUCTION}

The contents of Hanford's 177 underground storage tanks include a mixture of sludge, salt cake and alkaline supernatant liquids. The insoluble sludge fraction of the waste consists of metal oxides and hydroxides and contains the bulk of many radionuclides. The salt cake, generated by extensive evaporation of aqueous solutions, consists primarily of dried sodium salts. The supernates consist of concentrated aqueous solutions of sodium and potassium nitrate salts. The bulk of the water soluble radionuclides such as ${ }^{137} \mathrm{Cs}$ are contained in the water soluble salt cake and supernatant solutions.

Although the pretreatment and disposal requirements are still being defined, one of the first steps in most pretreatment scenarios will be a salt cake dissolution and sludge wash step followed by a solids/liquid separation. Most of the cesium is expected to be in the aqueous liquids and it is these solutions that are the focus of the cesium ion exchange removal process. This process is being designed with the goal of removing enough cesium so that the resulting low-level waste (LLW) will meet the NRC 10CFR61 class A limits for ${ }^{137} \mathrm{Cs}\left(1 \mathrm{Ci} / \mathrm{m}^{3}\right)$. The separated cesium may be concentrated and vitrified for disposal in the high-level waste repository. The decontaminated aqueous liquid will be solidified as a LLW grout for near-surface disposal.

The technology for Cs decontamination of high-level alkaline wastes and sludge wash waters is being developed at the Hestinghouse Hanford Company (WHC), Richland, Washington (Bray et al. 1989b; Bray et al. 1990a; Bray et al. 1991a; Bray et al, 1992); the Westinghouse Savannah River Company (WSRC), Aiken, South Carolina (Bibler et al, 1989c; Bray et al, 1990b); and at the West Valley Nuclear Services Company, Inc. (WVNS) in West Valley, New York (Bray et a1, 1984; Kurath et al, 1989d; Bray et al, 1991b). Using this technology as a starting point, experimental studies are being conducted by Pacific Northwest Laboratory $(\mathrm{PNL})^{1}$ to evaluate the performance of ion exchange processes and newly emerging technologies using simulated and actual Hanford wastes.

(1) PNL is operated for the U.S. Department of Energy by Battelle Memorial Institute. 


\subsection{OBJECTIVES}

The overall objective of the WHC program is, 1) to evaluate ion exchange materials for the recovery of cesium from alkaline wastes, 2) to determine their loading and elution capacities, 3) to determine the physical life cycle (including radiation and chemical stability) for selected ion exchangers, 4) to determine if basic ion exchange data can be applied to a broad range of tank wastes, and 5) to provide credible laboratory data for engineering-scale evaluation and ion exchange media selection. The goal will be to provide the technology to produce a Class $A$ waste. The results presented in this document provide initial test cesium loading and elution results for ion exchange column operations for two selected ion exchange resins under a limited range of conditions. Data in this report can be found in PNL laboratory record books BNW 54705 and BNW 55026. 


\subsection{EXPERIMENTAL}

Experimental work completed in FY 1992 for cesium recovery included the determination of cesium batch distribution coefficients for three exchangers and two waste forms (Bray et a1. 1992). FY 1993 experimental work included selected additional batch data and the initiation of ion exchange column studies. Ion exchange processes being investigated can be applied over a wide range of alkaline tank wastes. Complexant Concentrate (CC) and Neutralized Current Acid (NCAW) wastes were selected for the initial FY 1992 investigation. CC wastes represent a high sodium waste containing organic complexants. NCAW represents a high sodium waste containing a low organic coritent. The FY 1992 study showed that there was no difference between waste forms in the recovery of cesium from high sodium wastes. Because of the limited availability of actual waste, simulated NCAW solutions are being used to perform parametric studies. Actual wastes have only been used to obtain reference points and to verify that cesium ion exchange for simulated and actual wastes are equivalent. In 1989, radioactive waste from Tank 101AW was used to complete a batch contact with the Savannah River developed formaldehyde-resorcinol (BIB-DJ) resin (Bray 1989b). Additional radioactive tank wastes may be used after engineering-scale evaluation and ion exchange media selection has been completed.

\subsection{ION EXCHANGE SELECTION}

Two organic ion exchange resins were selected for the ion exchange column investigation; a granular phenol-formaldehyde condensate polymer ion exchange resin (CS-100) with carboxylic acid functional groups prepared by the Rohm and Haas Co., and a resorcinol-formaldehyde ion exchange resin (BIB-DJ). The BIB-DJ resin was first prepared by $D r$ Jane Bibler and Dr. Dick Wallace at the Westinghouse Savannah River Laboratory. The BIB-DJ resin is currently being manufactured by the Boulder Scientific Co, Mead, CO. Coordination continues between PNL, WHC and Dr. Jane Bibler of WSRC to test and verify the BIB-DJ resin (Bibler 1989C). 


\subsection{VARIABLES TO BE CONSIDERED TO OBTAIN COLUMN OPERATION DATA}

The effect on cesium loading and breakthrough was measured during column operation by selecting time-dependent variables (superficial velocity, bed volumes per hour, or flow rate). Other effects such as temperature or feed variables ( $\mathrm{Na}$ to $\mathrm{K}$ mole ratio and $\mathrm{OH}^{-}$) may be the subject of future column tests.

\subsection{EQUIPMENT DESCRIPTION}

The equipment consists of a constant temperature water bath, an analytical balance, temperature controlled ion exchange columns, and gamma counting equipment.

\subsubsection{Ion Exchange System}

The ion exchange column system consists primarily of six ion exchange columns, feed storage bottles, pumps and effluent weighing bottles. The glass columns each have a maximum capacity of $200 \mathrm{~mL}$ of ion exchange material. They are $2.54 \mathrm{~cm}$. in diameter and $41.9 \mathrm{~cm}$. tall (including head space for solution above the resin bed). They are equipped with water jackets connected to a water bath so that a constant temperature may be maintained. The columns may be run as independent columns or can be connected in series. The solution to the columns is normally fed downflow through pumps from feed tanks. Column elution can be initiated upflow. The feed pump located just upstream of the first column is used to control the flow rate. A valve is located at the bottom of each column from which each column's effluent may be sampled as a function of time. The effluent from the final column is routed to the weighing bottle. The column volumes (cv's) of the effluent processed are determined by the effluent weight divided by the specific gravity of the feed. A $24,600 \neq 0.1-g$ balance is used to determine the weight of the effluent.

The operation of the ion exchange system for removing cesium, containing ${ }^{137}$ Cs tracer, from simulated NCAW alkaline salt solution was varied as each test procedure was developed. The influent and effluent counting rates were measured to determine optimum performance of the ion exchange columns as a function of time and feed flow. 


\subsubsection{Single Column Configuration}

Single column configuration operation consists of individual ion exchange columns operated independently. The columns were operated 24 hours/d until the objective of the test was met.

\subsubsection{Multi-Column Configuration}

Multi-column operations can be performed by connecting two to six columns in series. The columns were operated 24 hours/d until the objective of the test was met. Samples were taken as a function of time at the bottom of each column. Care was taken to limit the amount of effluent in the head space on the top of each column so that the liquid mixing area did not perturb the overall results.

\subsection{PREPARATION OF SYNTHETIC WASTES}

Complexant concentrate (CC) and neutralized current acid waste (NCAW) were selected for the initial investigation (Bray et al, 1992). Organic CC waste represent a high sodium waste containing organic complexants. NCAW represents a high sodium waste with a low organic content. The results of that study show that the organic content of the waste had no effect on the basic cesium ion exchange data and that basic ion exchange data can be applied to a broad range of tank waste types. For this study, simulated solutions were prepared to represent NCAW. The ion concentration of NCAW is shown in Table 3.1.

TABLE 3.1. Neutralized Current Acid Waste - Synthetic Test Solution

\begin{tabular}{|c|c|}
\hline Species & NCAW, M \\
\hline $\mathrm{Na}$ & 5.0 \\
\hline K & 0.12 \\
\hline $\mathrm{Rb}$ & $5.0 \mathrm{E}-5$ \\
\hline Cs & $5.0 E-4$ \\
\hline & 0.43 \\
\hline OHffree) & $\begin{array}{l}0.15 \\
3.4\end{array}$ \\
\hline $\mathrm{CO}_{3}$ & 0.23 \\
\hline & 0.089 \\
\hline $\begin{array}{l}\mathrm{NO}_{2} \\
\mathrm{NO}_{3}\end{array}$ & $\begin{array}{l}0.43 \\
1.69\end{array}$ \\
\hline
\end{tabular}




\subsection{ION EXCHANGE COLUMN TEST INSTRUCTIONS}

The conditions selected for the initial exchange column loading tests were, to determine the effect of the time-dependent variables (superficial velocity or bed volumes per hour) for cesium loading, to keep the temperature $\left(25^{\circ} \mathrm{C}\right.$ ) and feed variables (Na+ concentration, $\mathrm{Na} / \mathrm{Cs}$ mole ratio) constant during the test series; to use an ion exchange column consisting of one to three $200 \mathrm{~mL}$ segments; to obtain samples between each segment; and to continue operation until the final column had a $C s C / C o$ value of 1 ( $C=$ concentration in the effluent, and $C_{0}=$ concentration in the influent).

\subsubsection{Candidate Ion Exchanger Preparation}

Two materials were tested using variable column configurations, CS-100 and $\mathrm{BIB}-\mathrm{DJ}$. The original $\mathrm{NaOH}$ pretreatment of each exchanger is described below. Because the sodium treated BIB-DJ resin appeared to degrade during storage, the majority of the BIB-DJ column tests were then completed by using "as received" resin obtained from the center of the 55 gallon receiving drum.

The CS-100 and the initial BIB-DJ ion exchange resins were pretreated with sodium hydroxide, water washed, and dried. Approximately 10 liters of the "as received" organic ion exchange resin were treated in a large ion exchange column with 3-column volumes (cv) of $2 \mathrm{M} \mathrm{NaOH}$, washed with $6 \mathrm{cr}$ of distilled water, placed in a vacuum filter funnel, washed with $\mathrm{H}_{2} \mathrm{O}$, and damp dried in the filter for a predetermined time. The resin was then placed in screw-cap glass storage jars for use.

The amount of material to be placed in each column ( $200 \mathrm{~mL}$ ) was added by weight as determined by the following method. First, the specific gravity of the caustic treated CS-100 or BIB-DJ was determined (grams of the dry exchanger in a known volume of wet exchanger). This was accomplished by weighing the prewashed CS-100 or BIB-DJ exchanger into a $200 \mathrm{~mL}$ volumetric cylinder containing water to a final tap volume of $200 \mathrm{~mL}$. This specific gravity $(\mathrm{g} / \mathrm{mL})$ was then used to determine the weight of $200 \mathrm{~mL}$ of resin used in the columns.

To load the resin into each column, the column was filled with $2 \mathrm{M} \mathrm{NaOH}$ and the ion exchange resin added based on weight. Each column was back flushed with $2 \mathrm{M} \mathrm{NaOH}$ to remove resin fines before being connected in series. 
The temperature of the water jacketed columns was controlled at $25 \pm 2^{\circ} \mathrm{C}$. The ion exchange and pump system was flushed and tested using at least 3-cr of 2M $\mathrm{NaOH}$ solution at a flow rate requested for the specific test.

To initiate the ion exchange column test, the solution head on the top of each column was reduced to the minimum. The columns were then connected as instructed and the excess $2 \mathrm{M} \mathrm{NaOH}$ above each exchange bed removed through the bottom sampling valve. NCAW feed was then started through the first column and the liquid heads above each column reestablished and held at $\sim_{1-i n c h}$.

When the last column was loaded to $>90 \%$ Cs breakthrough $\left[{ }^{137} \mathrm{Cs}\right.$ effluent count rate $(C) \div{ }^{137}$ Cs feed count rate $\left.(C O)=1\right]$, the test was terminated. The system was then flushed downflow with $3 \mathrm{cv}$ of $2 \mathrm{M}$ sodium hydroxide solution and then with $6 \mathrm{cv}$ of water at $(2 \mathrm{cv} / \mathrm{h})$. All columns were then placed in an interstitial water condition. Sodium hydroxide (2M) wash was used to remove residual feed containing sodium aluminate from the system prior to water washing, to prevent aluminum precipitation due to a lowering of the $\mathrm{pH}$. The loaded and washed columns were then detached and individually eluted using formic acid or nitric acid (Section 4.3).

\subsection{BATCH DISTRIBUTION}

A batch distribution coefficient is a measure of the overall ability of the solid phase to remove an ion from solution (Bray 1989a). Batch distribution data are reported as radionuclide distribution coefficients $\left(K_{d}\right)$ and/or $\lambda$. Under certain conditions, $\lambda$ is approximated by the bed volumes processed at $0.5 \mathrm{C} / \mathrm{Co}_{0}$ breakthrough. $K_{d}$, in units of $\mathrm{mL} / \mathrm{g}$ (volume of solution per mass of dry exchanger), represents a theoretical volume of solution that can be processed per mass of exchanger. To convert to $\lambda$, the $K_{d}$ value is multiplied by the bed density of the exchanger $\left(\rho_{b}\right)$ to obtain a value equivalent to the volume of the solution processed per volume of exchanger. The equation for the determination of $k_{d}$ is:

$$
K_{d}=C_{s} \div C_{1}, \mathrm{~mL} / g \text {, }
$$

where $C_{s}=$ the concentration of the radionuclide exchanged on the solid phase ( $\mathrm{C}$ or $\mathrm{g}$ of radionuclide/g of anhydrous material), and

$C_{1}=$ the concentration of the radionuclide remaining in the liquid phase after batch contact ( $\mathrm{Ci}$ or $\mathrm{g}$ of radionuclide/mL). 
The equation for the determination of $\lambda$ is:

$$
\lambda=K_{d} \times \rho_{b} \text {, dimensionless, }
$$

where $\lambda$ represents the number of ion exchange bed volumes of feed that can be loaded on an exchanger (column volumes or $\mathrm{cv}$ ). The value for $\lambda$ is artificial because it is difficult, in practice, to achieve $100 \%$ loading of a column. 


\subsection{RESULTS AND DISCUSSION}

\subsection{BATCH EQUILIBRIUM STUDIES}

During FY92 and FY93, cesium batch distribution coefficient results were completed for four cesium ion exchangers, CS-100, BIB-DJ, IONSIV IE-96 produced by the UOP Co., and the Sandia National Laboratory crystalline silico-titanates (Bray et al, 1992; Bray et al, 1993). The results for the organic resins CS-100 and BIB-DJ were determined as a function of the equilibrium sodium to cesium mole ratio, Figures 4.1 and 4.2 . If we apply these data to ion exchange column experiments, using a NCAW feed with a Na/Cs mole ratio of $10^{4}$, we can draw a plane through the data to determine $\lambda$ as a function of the sodium concentration, Figure 4.3. This provides an equivalent estimate of the cesium loading capacity for these exchangers. Thus prior to testing CS-100 and BIB-DJ resins in an ion exchange column system, a cesium loading for $5 \mathrm{M} \mathrm{Na}^{+} \mathrm{NCAW}$ was projected to be $30 \mathrm{cv}$ and $180 \mathrm{cv}$, respectively (at Cs C/Co of 0.5 ).

\subsection{ION EXCHANGE COLUMN LOADING STUDIES}

Cesium loading experiments were performed using the CS-100 and BIB-DJ resins. The tests were designed to determine the effect of flow rate on the cesium loading characteristics of the resin being tested. Tests that have been completed are shown in Table 4.1.

TABLE 4.1 Cesium Loading Experiments

$(\mathrm{mL} / \mathrm{hr})$

\# of Columns Flow Rate
Test \# Resin Used

Test \# Resin Used in Series

$\begin{array}{lllr}1 & \text { CS-100 } & 1(A) & 1,200 \\ 2 & \text { BIB-DJ } & 1(B) & 1,200 \\ 3 & \text { CS-100 } & 3(C, D, E) & 1,200 \\ 5 & \text { CS-100 } & 3(I, J, K) & 600 \\ 7 & \text { CS-100 } & 3(0, P, Q) & 1,800 \\ 8 & \text { BIB-DJ(as rec) } & 3(R, S, T) & 1,800\end{array}$




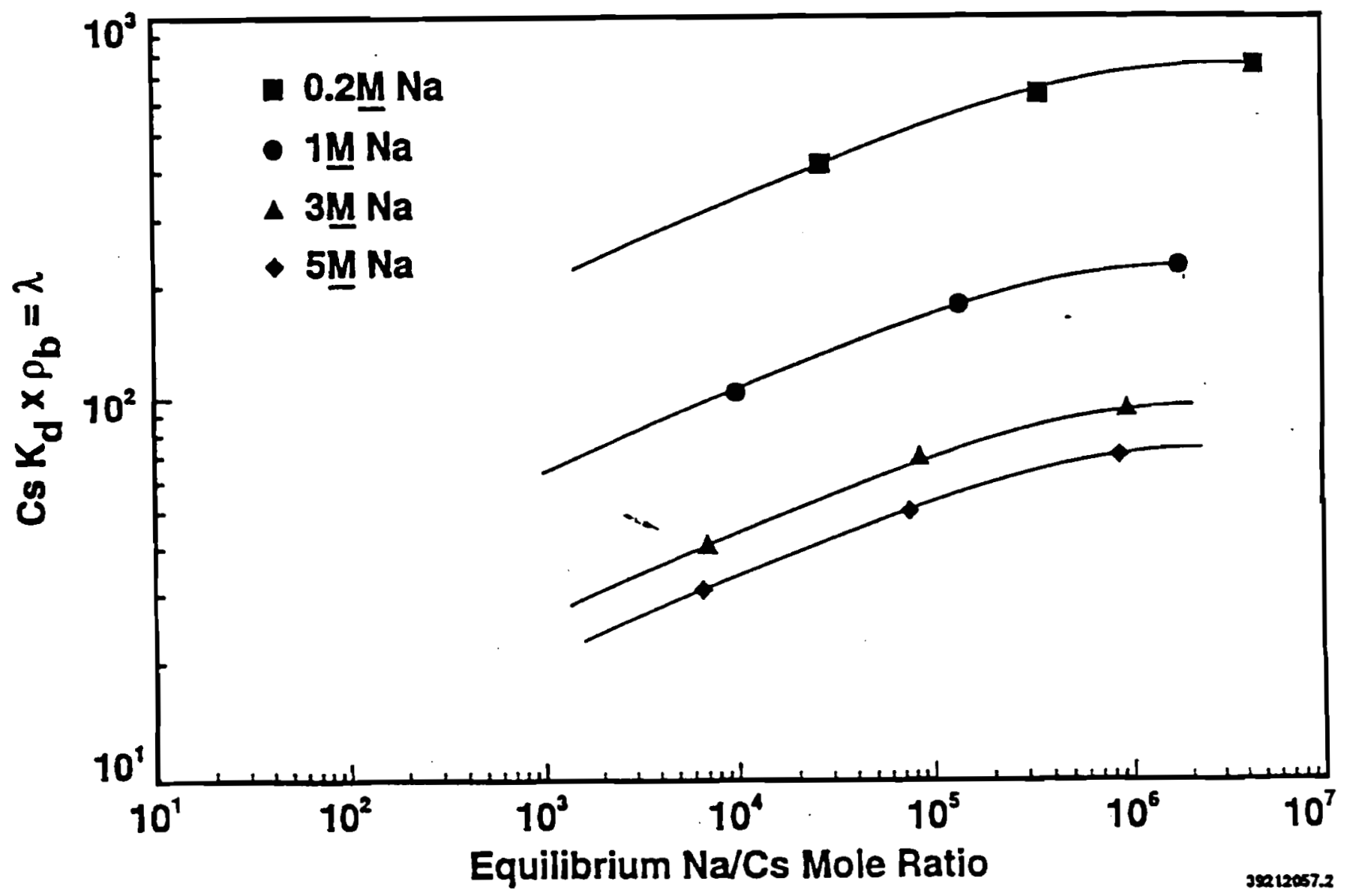

FIGURE 4.1. Batch Distribution Studies - CS-100 and NCAW 


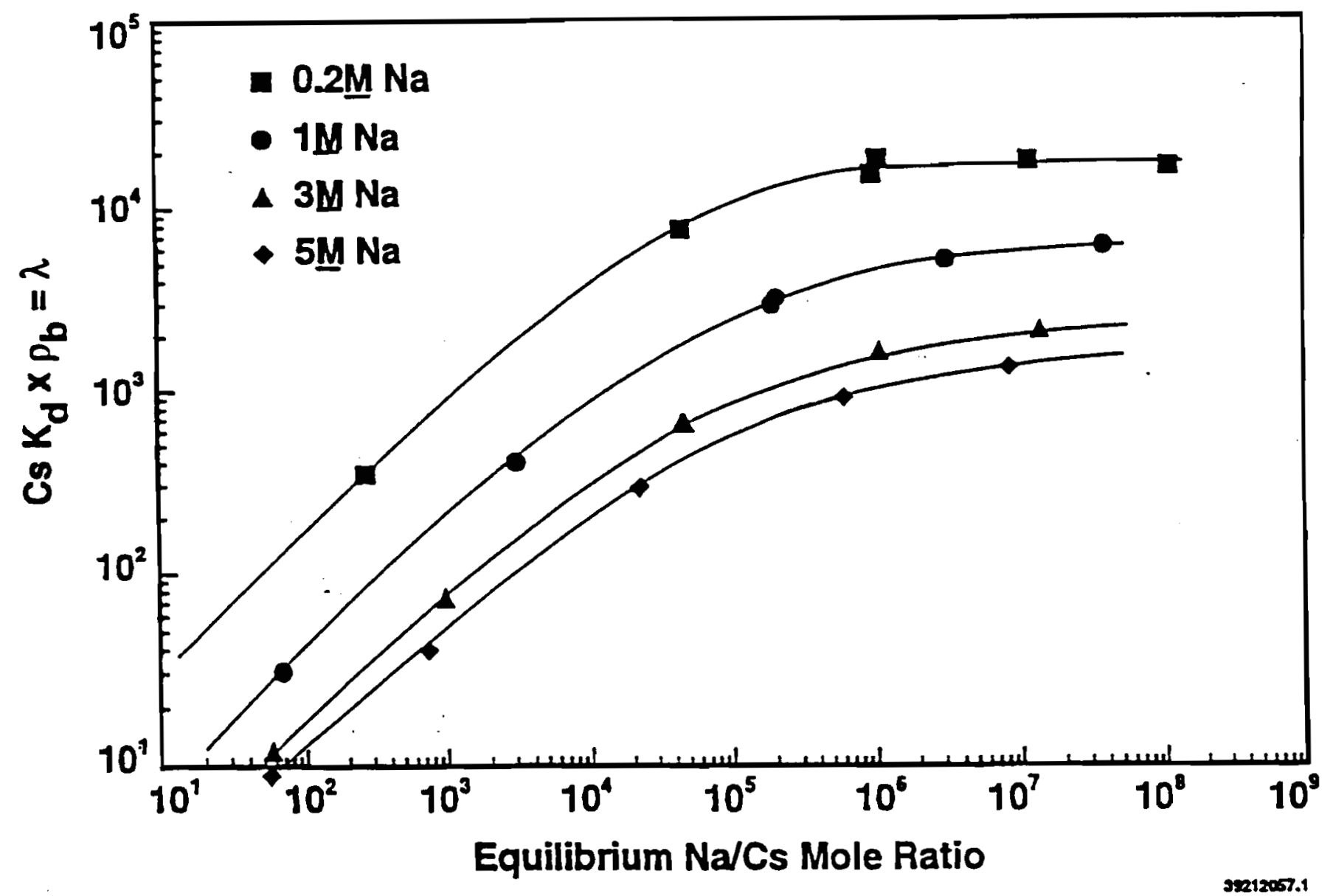

FIGURE 4.2. Batch Distribution Studies - BIB-DJ and NCAW 


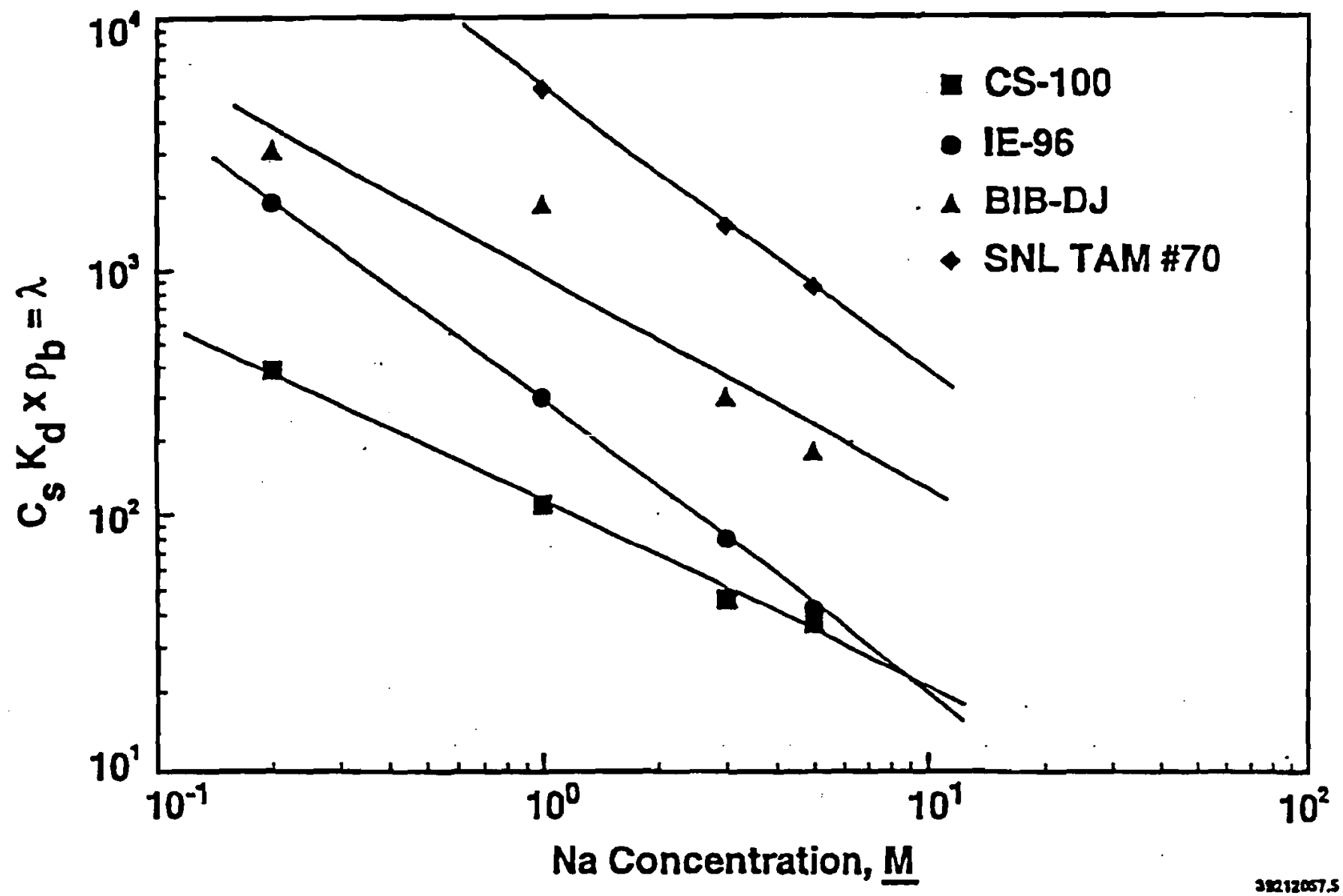

FIGURE 4.3. Comparison Between IE-96, CS-100, BIB-DJ and TAM-70 at an Equilibrium $\mathrm{Na} / \mathrm{Cs}$ Mole Ratio of $10^{4}$ 


\subsubsection{CS-100 Loading Studies}

The initial cesium loading test with $\mathrm{NaOH}$ pretreated $\mathrm{CS}-100$ resin was completed using a single column (Test-1, Column A) at $6 \mathrm{cv} / \mathrm{hr}$, Figure 4.4 . The initial detectable cesium breakthrough $(\mathrm{C} / \mathrm{Co}=0.0001)$ occurred at $5 \mathrm{cv}$. The Cs $0.5 \mathrm{C} / \mathrm{Co}$ value was $30 \mathrm{cv}$ and agrees well with that predicted from the batch distribution data, Figure 4.3. The next three tests (Test-5, -3, and 7) involved the use of three columns in series, Figures $4.5,4.6$, and 4.7. The flow rate through the first column in each series was. 3, 6, and $9 \mathrm{cv} / \mathrm{hr}$, respectively. The column volumes at which the initial detectable cesium breakthrough $(\mathrm{C} / \mathrm{CO}=0.0001)$ was detected decreased with increasing flow rate; $10 \mathrm{cv}$ to $3.5 \mathrm{cv}$. In each case, the column volumes of feed passed through the system at $C_{s} C / C_{0}=0.5$ was 30,60 and 90 for the three columns in series.

Columns in series $(C, D, E)$ can be viewed as three single columns, i.e., C $(200 \mathrm{~mL}), C D(400 \mathrm{~mL})$ and $\operatorname{CDE}(600 \mathrm{~mL})$. A flow rate of $1,800 \mathrm{~mL} / \mathrm{h}$ through this series can be used to obtain data at three residence times, i.e., $9 \mathrm{cv} / \mathrm{h}$, $4.5 \mathrm{cv} / \mathrm{h}$ and $3 \mathrm{cv} / \mathrm{h}$. Selected results for the four CS-100 ion exchange tests were combined to obtain a better picture of cesium loading as a function of the residence time, Figure 4.8. The column volumes at which the initial detectable cesium breakthrough $\left(C / C_{0}=0.0001\right)$ was noted varied from $\sim 2.5$, $3.5,7$ to $\sim 19 \mathrm{cv}$ as the flow rate varied from $9,6,3$ to $1 \mathrm{cv} / \mathrm{hr}$, respectively. However, all of the breakthrough curves merged at $0.5 \mathrm{C} / \mathrm{Co}$ or $\sim_{30} \mathrm{cv}$.

Because there is great interest in the above information for engineering scale-up, selected data was replotted as a function of feed velocity. Assuming a laboratory column with a $5.07 \mathrm{~cm}^{2}$ area and a flow rate of $3 \mathrm{cv} / \mathrm{h}$, the superficial velocity through the column varied from 1.97 to $5.92 \mathrm{~cm} / \mathrm{min}$. These data show insignificant difference between the three velocities, Figure 4.9. This would indicate that the data obtained from the laboratory $200 \mathrm{~mL}$ ion exchange columns can be used to directly scale-up to large-scale processing columns. This has been previously demonstrated at West Valley Nuclear Service Co., West Valley, NY when the results of the PNL $200 \mathrm{~mL}$ columns were used to directly scale-up the WV 3-foot by 10 feet high zeolite columns being used for the removal of cesium from PUREX alkaline waste (Kurath 1989d). 


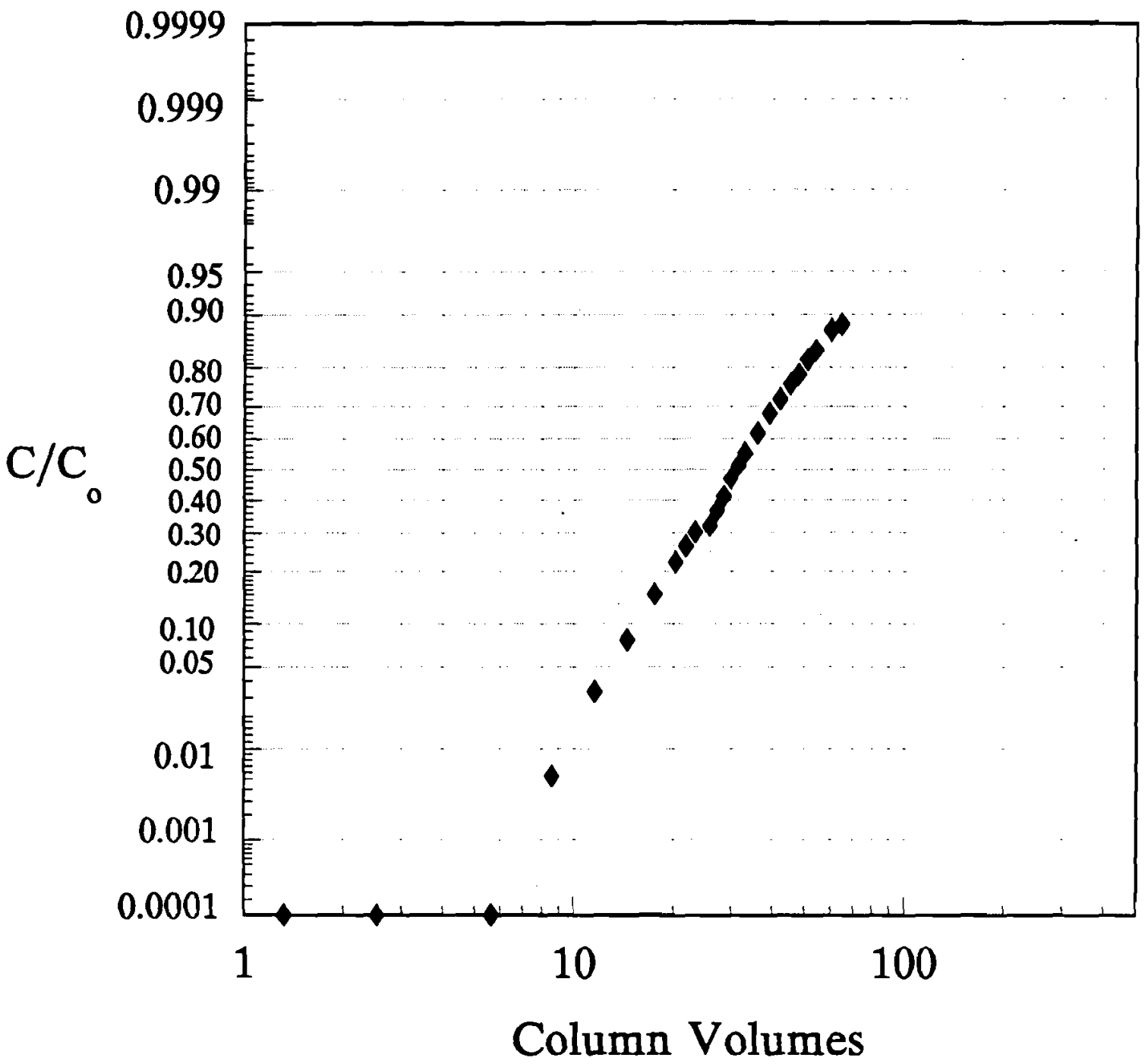

FIGURE 4.4. CS-100 Cesium Loading Test - Column $A ; 1,200 \mathrm{~mL} / \mathrm{hr}$ 


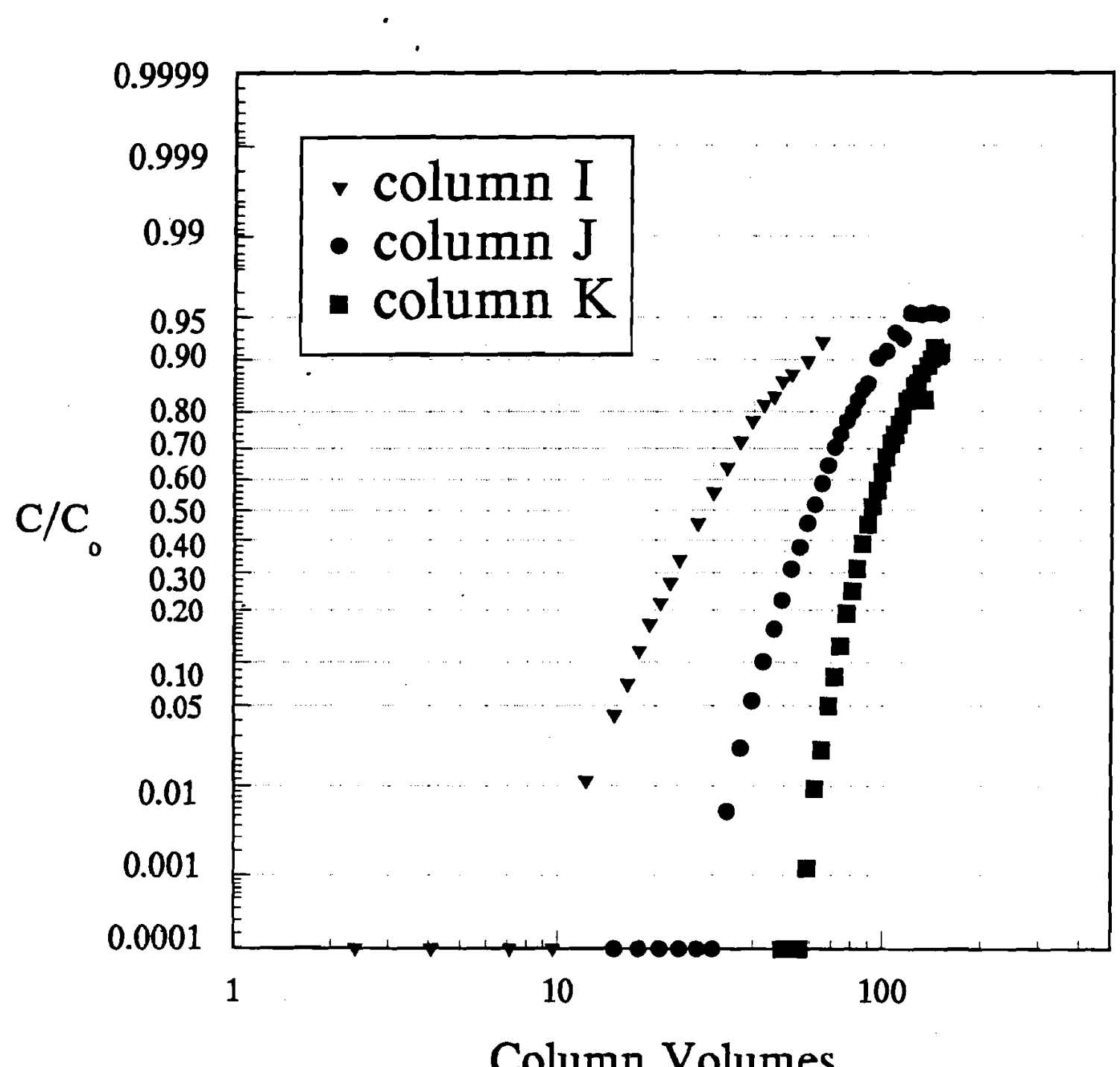

FIGURE 4.5. CS-100 Cesium Loading Test - Columns I, J, K; $600 \mathrm{~mL} / \mathrm{hr}$ 


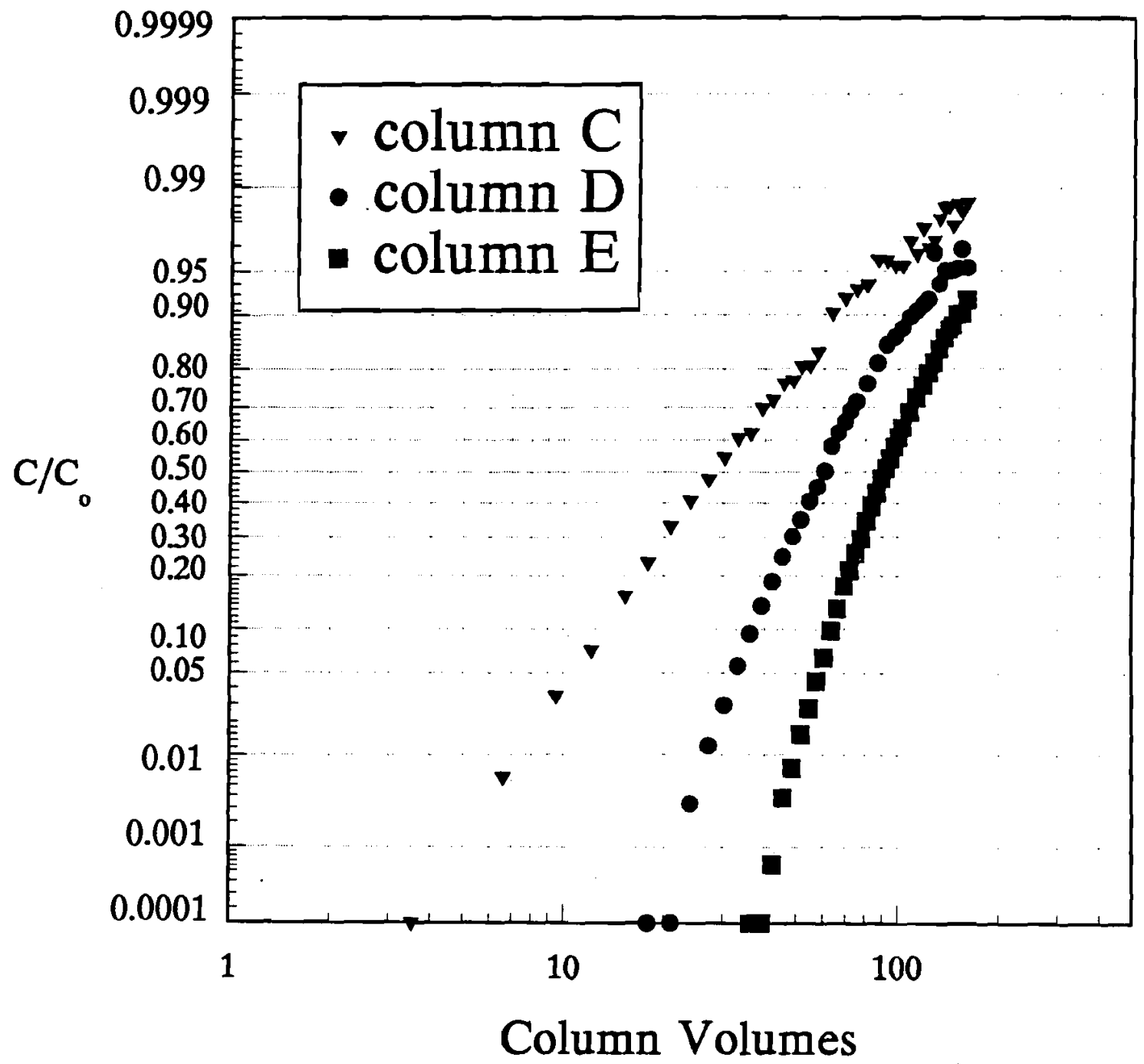

FIGURE 4.6. CS-100 Cesium Loading Test - Columns C, D, E; 1,200 mL/hr 


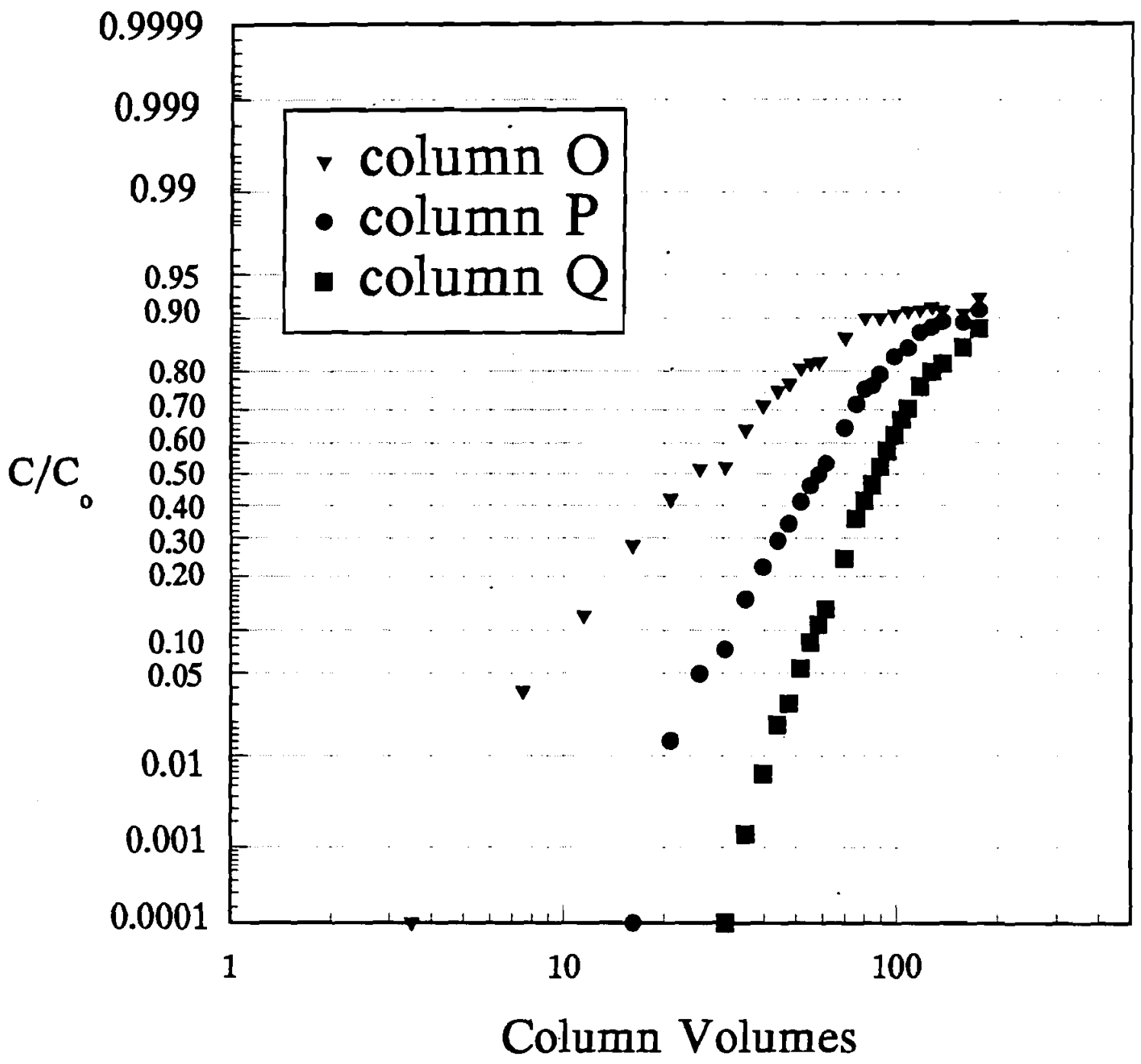

FIGURE 4.7. CS-100 Cesium Loading Test - Columns $0, P, Q_{i} 1,800 \mathrm{~mL} / \mathrm{hr}$ 


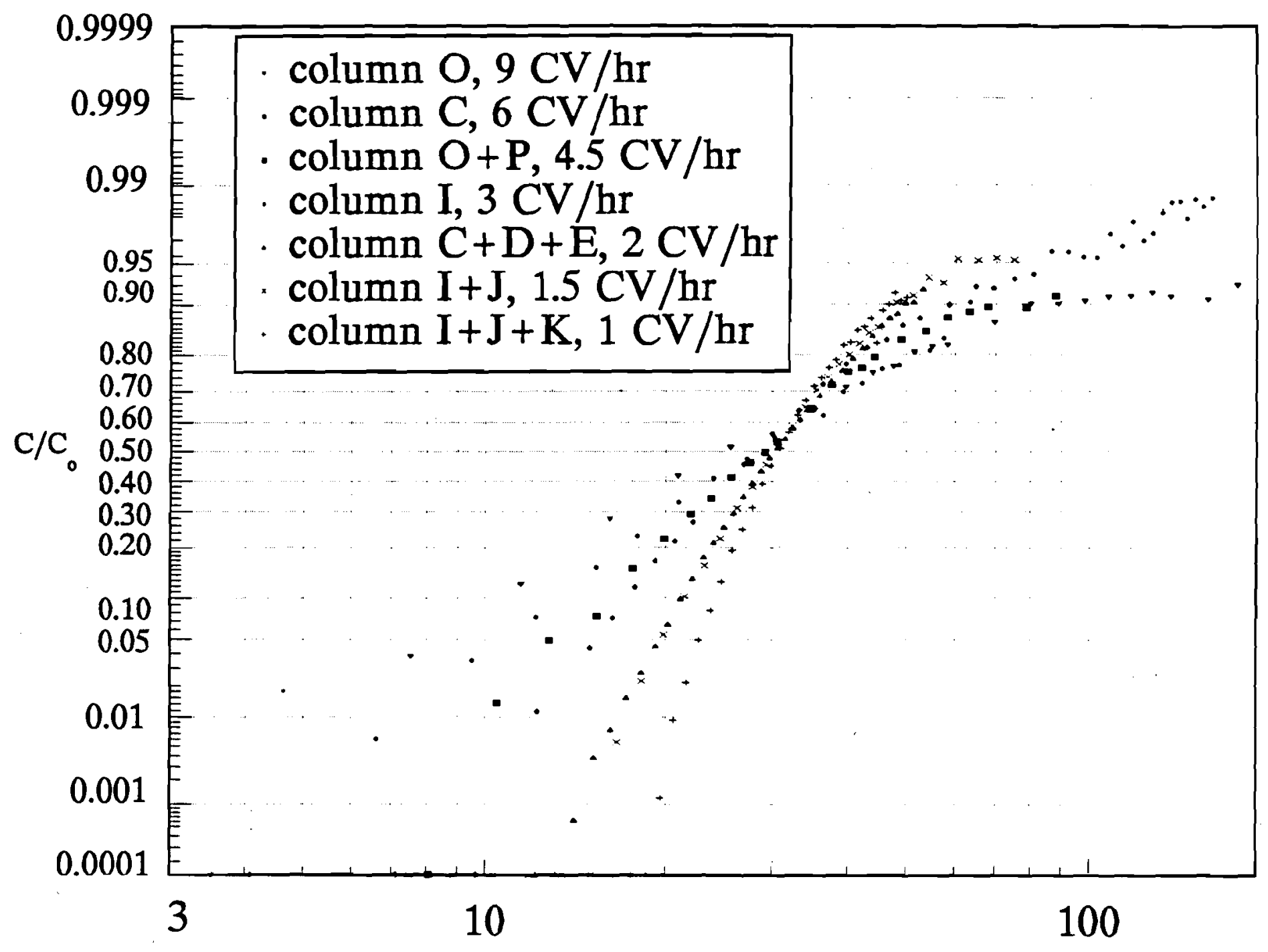

Column Volumes

FIGURE 4.8. CS-100 Cesium Loading Results - Cs Breakthrough as a Function of Flow Rate 


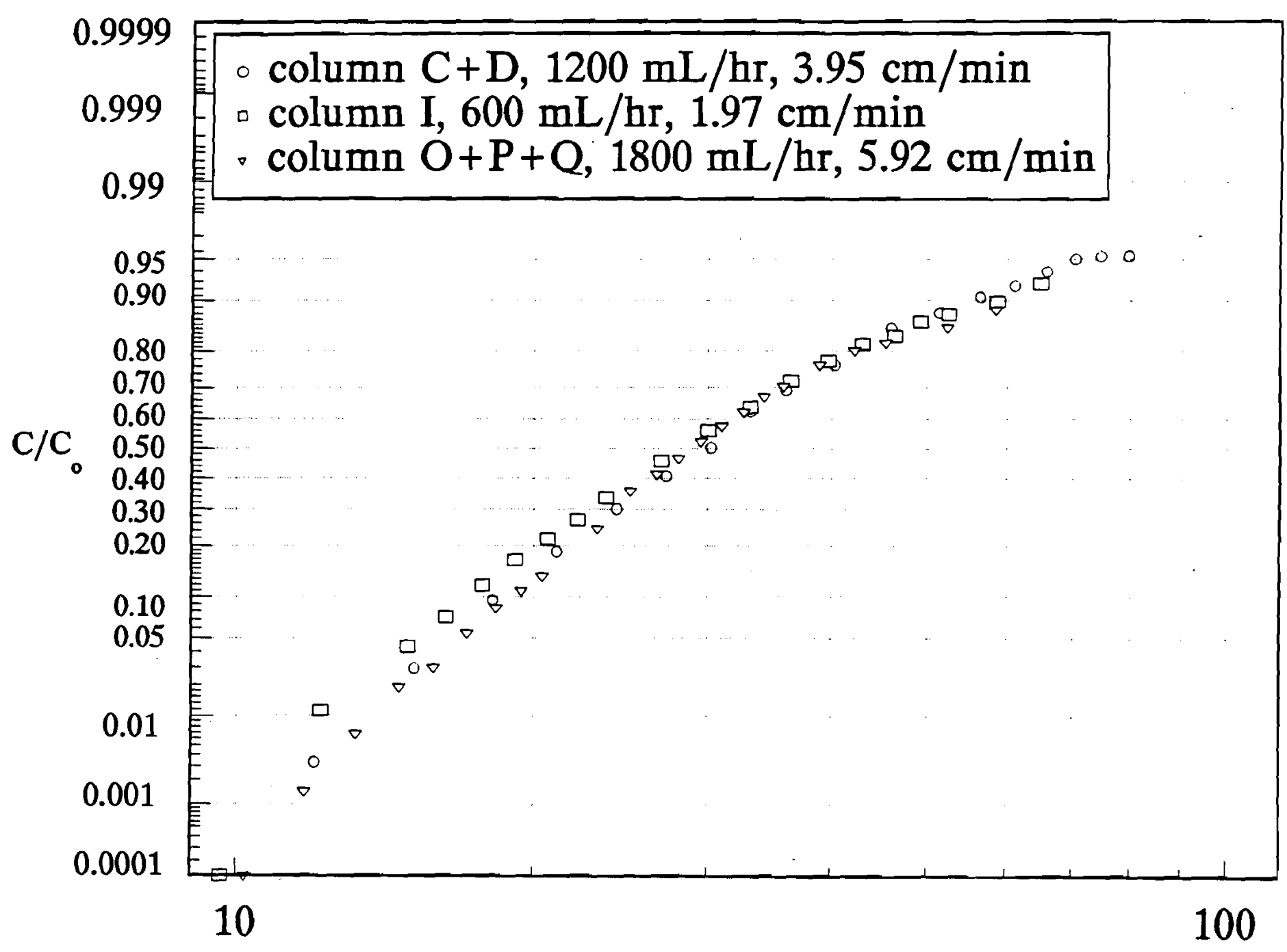

Column Volumes

FIGURE 4.9. CS-100 Cesium Loading Results - Cs Breakthrough as a Function of Flow Velocity 


\subsection{2 $\mathrm{NaOH}$ Washed BIB-DJ Loading Studies}

The initial cesium loading test with $\mathrm{NaOH}$ Washed $\mathrm{BIB}-\mathrm{DJ}$ resin was completed with a single column (Test-2, Column B) at $6 \mathrm{cv} / \mathrm{hr}$, Figure 4.10 . The initial detectable cesium breakthrough $\left(\mathrm{C} / \mathrm{CO}_{0}=0.0001\right)$ occurred at $23 \mathrm{cr}$. The Cs $0.5 \mathrm{C} / \mathrm{Co}_{0}$ value was $80 \mathrm{cv}$ (versus $30 \mathrm{cv}$ for CS-100 under the same conditions, Figure 4.4 ) but does not agree with the $180 \mathrm{cv}$ value that was predicted from the batch distribution data, Figure 4.3. Further multiple column tests (Section 4.2.3) were placed on hold until the apparent loss in capacity of the resorcinol-formaldehyde resin was understood.

\subsubsection{Batch Distribution Studies to Determine BIB-DJ Resin Characteristics}

In 1987, Dr. Jane Bibler, WSRC, provided PNL with a liter sample of research-grade resorcinol-formaldehyde resin (BSC-187) to complete a series of laboratory ion exchange column (200 $\mathrm{mL}$ ) tests (Bibler 1989). Dr. Bibler also had a large quantity of the resin made commercially by Boulder Scientific Co. (BSC), which was shipped to WSRC in a number of 55 gallon drums. To initiate the FY 1992 program for WHC, PNL purchased several cubic feet of resin directly from BSC from material left over from production of the multi 55gallon Bibler order. However, this material had a very poor Cs batch distribution value as compared with earlier Bibler analytical samples (BSC187). We then asked Dr. Bibler to send us material from one of the 55 gallon drums in storage. Since this was difficult to do in a short time period, a one gallon sample was withdrawn from a 55 gallon drum by WSRC and sent to PNL. This material was treated with $2 \mathrm{M} \mathrm{NaOH} \mathrm{(12-21-92)} \mathrm{and} \mathrm{immediately} \mathrm{used} \mathrm{for}$ batch distribution studies (Bray et al 1992). This also provided the material that was later (March, 1993) used for the first $200 \mathrm{~mL}$ ion exchange column test (Figure 4.10), which indicated that the material had degraded since it was first treated for the batch tests.

To determine differences between the one gallon sample, the 55 gallon drum, and the initial resin $(B S C-187), 0.19$ samples of the organic resins were batch contacted (in duplicate) at $25^{\circ} \mathrm{C}$ for $72 \mathrm{hrs}$ with synthetic NCAW, Table 3.1. The $C s K_{d}$ values for various pretreatment conditions show that the 1-gallon and the 55-gallon BIB-DJ materials appear to be the same, Table 4.2. The 1987 (BSC-187) material appears to have degraded. No pretreatment 


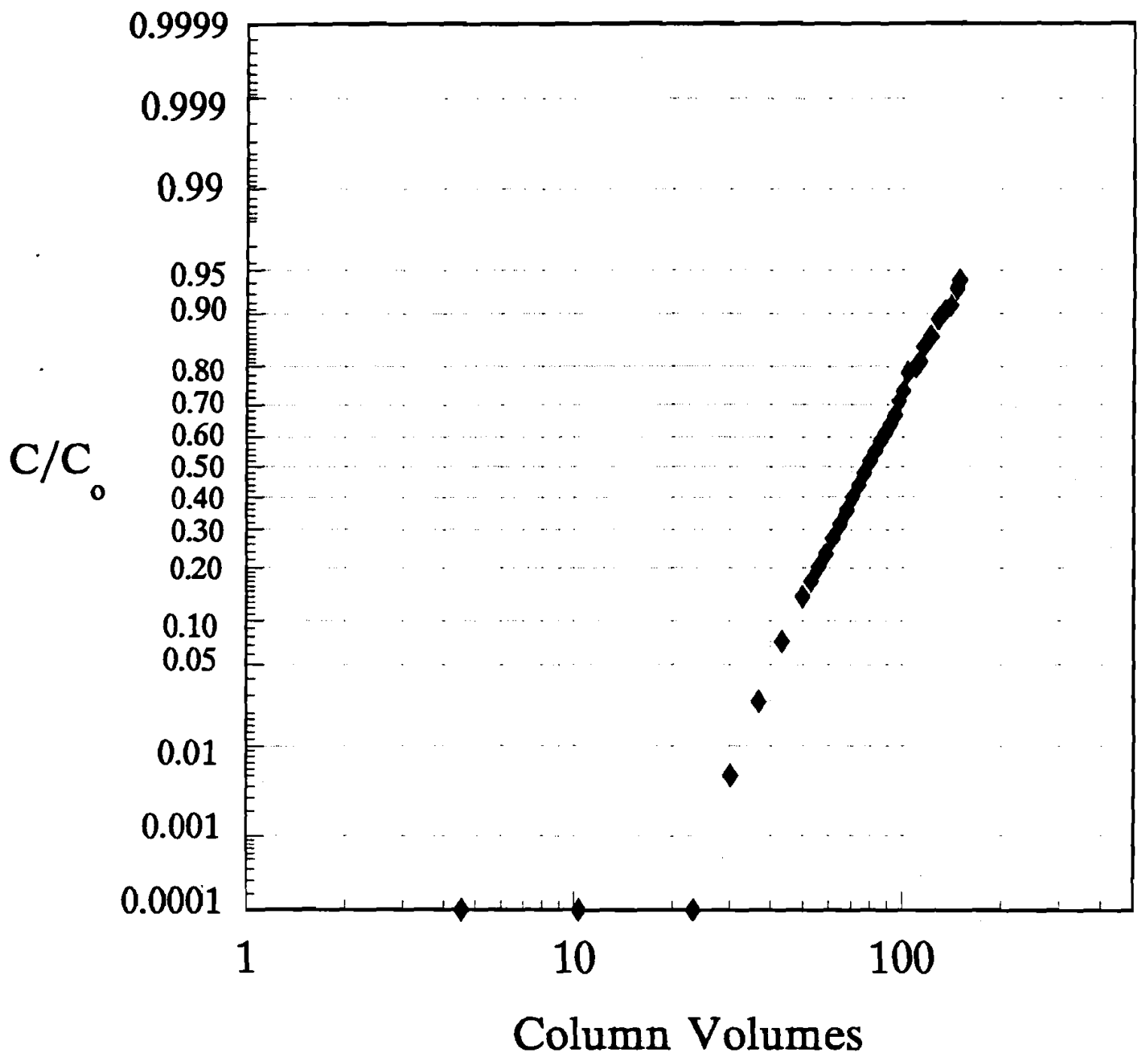

FIGURE 4.10. BIB-DJ Cesium Loading Test - Column $B_{i} 1,200 \mathrm{~mL} / \mathrm{hr}$ 4.13 
provided the highest $C s K_{d}$ values for the resin in the drums. Water appears to degrade the resin. However, soaking the water treated resin in $\mathrm{NaOH}$ for $\sim 16$ hrs partially restored the resin to the "as received" values. Based on

IABLE 4.2. Cesium Batch Distribution Studies for BIB-DJ

Conditions: $0.1 \mathrm{~g}$ samples in duplicate, $25^{\circ} \mathrm{C}, 72 \mathrm{hrs}$ contact, synthetic NCAW (Table 3.1)

Pretreatment Conditions

BIB-DJ Cs $K$ Values

$5 \min , 2 \mathrm{M} \mathrm{NaOH}{ }^{2}$

$60 \mathrm{~min}, 2 \overline{\mathrm{M}} \mathrm{NaOH}$

16 hrs, $2 \bar{M} \mathrm{NaOH}$

$68 \mathrm{hr} \mathrm{H} \mathrm{H}_{2}, 5 \mathrm{~min}, 2 \mathrm{M} \mathrm{NaOH}$

$68 \mathrm{hr} \mathrm{H} 20,60$ min, $2 \bar{M} \mathrm{NaOH}$

$68 \mathrm{hr} \mathrm{H} 2 \mathrm{O}, 16 \mathrm{hrs}, 2 \overline{\mathrm{M}} \mathrm{NaOH}$

No $\mathrm{H}_{2} \mathrm{O}$, no $\mathrm{NaOH}$

\begin{tabular}{|c|c|c|}
\hline BIB-D & Cs K d Valu & \\
\hline 55 gal Drum & 1 gal Drum & BSC-187 (1987) \\
\hline $\begin{array}{l}870,906 \\
989,980 \\
959,947\end{array}$ & $\begin{array}{l}856,880 \\
939,969 \\
765,803\end{array}$ & $\begin{array}{ll}237, & 252 \\
275, & 330 \\
210, & 184\end{array}$ \\
\hline $\begin{array}{ll}506, & 533 \\
493, & 491 \\
761, & 780\end{array}$ & $\begin{array}{l}499,492 \\
506,467 \\
920,915\end{array}$ & $\begin{array}{ll}209, & 249 \\
191, & 171 \\
261, & 233\end{array}$ \\
\hline 035,1054 & 1060,1033 & 355,30 \\
\hline
\end{tabular}

this information, the 55 gallon drum was again tested by varying the pretreatment conditions. The results again show that the best material in the 55 gallon drum is 10 inches into the drum with no pretreatment, Table 4.3. That the original resin (1-gallon) that was $2 \mathrm{M} \mathrm{NaOH}$ treated, water washed and air dried (12/21/92) had degraded, causing the poor ion exchange performance (Section 4.2.2). To test this theory, the BIB-DJ ion exchange column studies were resumed by using as received resin.

\subsubsection{BIB-DJ Loading Studies - No Pretreatment}

Three ion exchange columns were operated in series $(R, S$, and $T)$. The columns were each filled with $200 \mathrm{~mL}$ of BIB-DJ resin obtained from approximately 10-inches below the surface of the resin in the 55-gallon receiving drum. The object was to determine if the resin in the 55-gallon drum had deteriorated as compared with sodium-washed resin prepared (12/21/92) and tested earlier (Figure 4.4). The flow rate through the first column in

2 Followed by water washing and air drying. Heighed sample of air dried resin was heated to $105^{\circ} \mathrm{C}$ and used to adjust the air dried weights. 
TABLE 4.3. Cesium Batch Distribution Studies for BIB-DJ, 55 gallon Drum Conditions: $0.1 \mathrm{~g}$ samples in duplicate, $25^{\circ} \mathrm{C}, 72 \mathrm{hrs}$ contact, synthetic NCAW (Table 3.1)

\begin{tabular}{|c|c|}
\hline Pretreatment Conditions & $\begin{array}{l}\text { Cs } K_{d} \text { Values } \\
55 \text { gal Drum }\end{array}$ \\
\hline $\begin{array}{l}\text { Top of drum, 6M NaOH, } 72 \mathrm{~h} \\
\text { No } \mathrm{H}_{2} \mathrm{O} \text { wash }\end{array}$ & 1249,1229 \\
\hline $\begin{array}{l}\text { Top of drum, } 6 \mathrm{M} \mathrm{NaOH}, 24 \mathrm{~h} \\
\mathrm{H}_{2} \mathrm{O} \text { wash, vacuum dry }\end{array}$ & 1226,1221 \\
\hline Top of drum, air dry, $24 \mathrm{~h}$ & 1021,998 \\
\hline $\begin{array}{l}10 \text { inches into drum, no } \\
\text { pretreatment }\end{array}$ & 1294,1271 \\
\hline $\begin{array}{l}\text { Resin treated with } \mathrm{NaOH}, \\
\mathrm{H}_{2} \mathrm{O} \text {, and air dried on } \\
12-21-92 \text { used for batch } \\
\text { distribution studies } \\
\text { (Bray et al, 1992). } \\
1 \text {-gallon BIB-DJ }\end{array}$ & $247, \quad 262$ \\
\hline
\end{tabular}

series was $1,800 \mathrm{~mL} / \mathrm{hr}$ or $9 \mathrm{cv} / \mathrm{hr}$. The initial detectable cesium breakthrough $\left(\mathrm{C} / \mathrm{CO}_{0}=0.0001\right)$ was $100 \mathrm{cv}$. The column volumes of feed which passed through the first column (R) at $C s C / C O=0.5$ was 190 and agrees well with that predicted $(180 \mathrm{cr})$ from the batch distribution data, Figure 4.3. In each case, the column volumes of feed passed through the system $(R, S$, and $T$ ) at $C S C / C O=0.5$ was 190,380 and 570 for the three columns in series, Figure 4.11. There was no detectable breakthrough of the succeeding column prior to $0.95 \mathrm{C} / \mathrm{Co}$ breakthrough of the initial column. The resin in the 55 gallon drum (10-inches below the surface) was comparable to the initial batch distribution studies. The data in Table 4.3 confirms that the resin on the surface may be degraded, but that resin 10 inches into the drum is protected by the surface resin.

Columns in series ( $R, S$, and $T$ ) can also be viewed as three single columns, i.e., R $(200 \mathrm{~mL})$, RS $(400 \mathrm{~mL})$ and RST $(600 \mathrm{~mL})$. A flow rate of 1,800 $\mathrm{mL} / \mathrm{h}$ through this series was used to obtain data at three residence times, i.e., $9 \mathrm{cv} / \mathrm{h}, 4.5 \mathrm{cv} / \mathrm{h}$ and $3 \mathrm{cv} / \mathrm{h}$. The column volumes at which the initial 


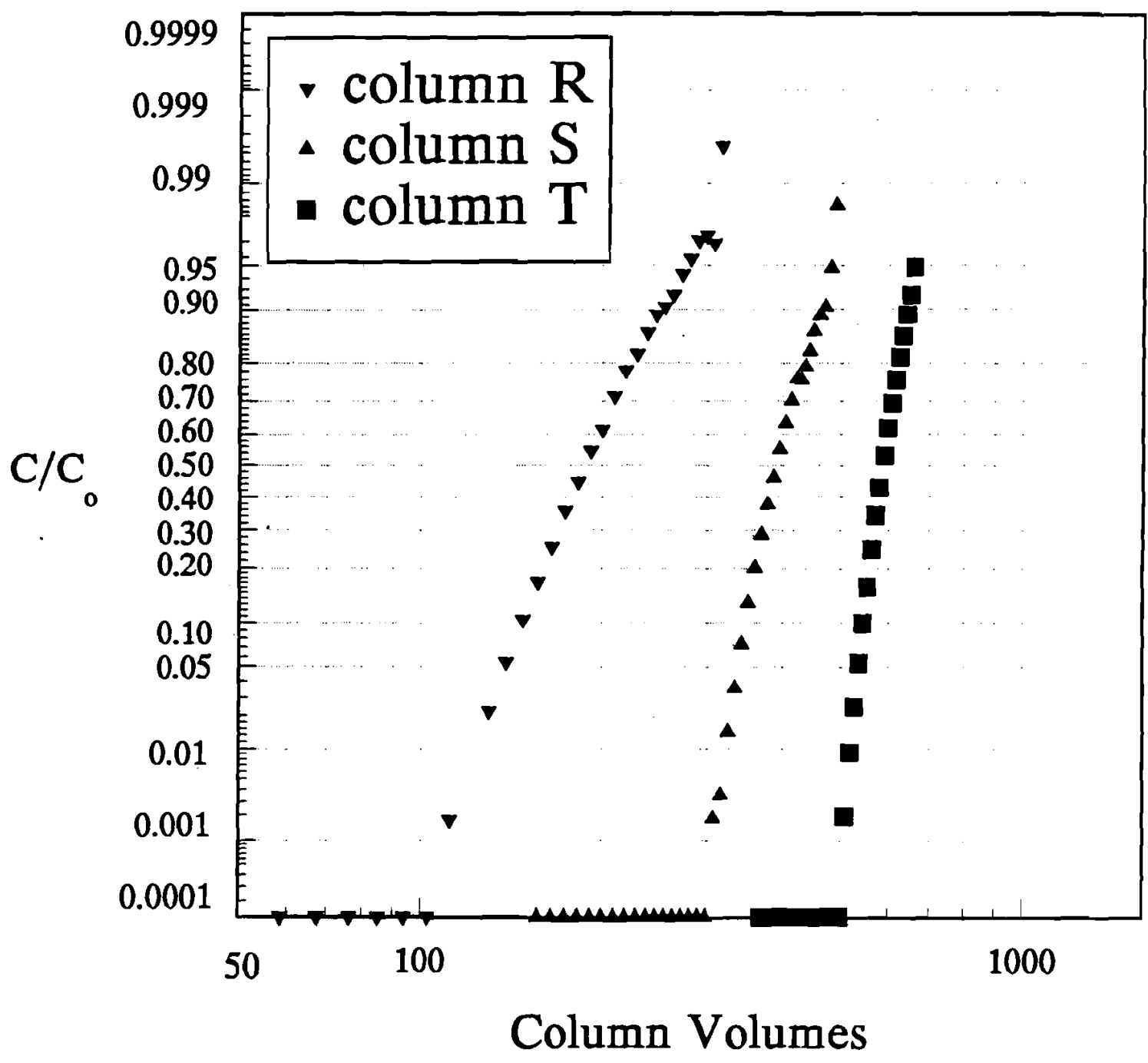

FIGURE 4.11. BIB-DJ Cesium Loading Test - Columns R, S, T; $1,800 \mathrm{~mL} / \mathrm{hr}$ 4.16 
detectable cesium breakthrough $\left(\mathrm{C} / \mathrm{Co}_{0}=0.0001\right)$ was noted varied from $100 \mathrm{cv}$, $140 \mathrm{cv}$ and $160 \mathrm{cv}$ as the flow rate varied from $9,4.5$ to $3 \mathrm{cv} / \mathrm{hr}$, respectively. However, all of the breakthrough curves merged at $\sim 0.5 \mathrm{C} / \mathrm{Co}$ of $190 \mathrm{cv}$ as expected, Figure 4.12. The results show that the BIB-DJ resin has a cesium capacity approximately 6.3 times that of CS-100 under similar conditions.

\subsection{ION EXCHANGE ELUTION STUDIES}

Cesium elution experiments were performed using the CS-100 and BIB-DJ cesium loaded resins (Section 4.2). The experiments were designed to determine the effect of flow rate, temperature, and type of acid eluate on the cesium elution characteristics of the resin being tested. The acid types were limited to nitric acid and formic acid. The concentration of the nitric acid was 1 imited to 0.1 molar due to the concern for auto catalytic reactions with the resin at higher acidities. Tests completed are shown in Table 4.4.

\section{TABLE 4.4 Cesium Elution Experiments}

\begin{tabular}{|c|c|c|c|c|c|}
\hline$\frac{\text { Column (Test) }}{A(1)}$ & $\frac{\text { Resin }}{\text { CS-100 }}$ & $\frac{\text { Eluent }}{0.1 \mathrm{M} \mathrm{HNO}}$ & $\begin{array}{l}\begin{array}{c}\text { Flow Rate } \\
(\mathrm{mL} / \mathrm{hr})\end{array} \\
\frac{1,200}{1,20}\end{array}$ & $\frac{\begin{array}{c}\mathrm{cv} / \mathrm{hr} \\
(200 \mathrm{~mL} / \mathrm{col} .)\end{array}}{6}$ & $\frac{\text { Temp. },{ }^{\circ} \mathrm{C}}{25}$ \\
\hline$c(3)$ & CS-100 & $0.05 \mathrm{M} \mathrm{HNO}_{3}$ & 1,200 & 6 & 25 \\
\hline$D(3)$ & CS-100 & $1 \underline{N} \mathrm{HCOOH}$ & 1,200 & 6 & 25 \\
\hline$E(3)$ & $C S-100$ & $0.5 \underline{\mathrm{N}} \mathrm{HCOOH}$ & 1,200 & 6 & 25 (not shown) \\
\hline$I(5)$ & $C S-100$ & $0.1 \underline{M} \mathrm{HNO}_{3}$ & 1,200 & 6 & 40 \\
\hline $\mathrm{J}(5)$ & $C S-100$ & $0.05 \mathrm{M} \mathrm{HNO}_{3}$ & 1,200 & 6 & 40 (not shown) \\
\hline$K(5)$ & CS -100 & $1 \underline{\mathrm{N}} \mathrm{HCOOH}$ & 1,200 & 6 & 40 \\
\hline $0(7)$ & CS -100 & $0.1 \mathrm{M} \mathrm{HNO}_{3}$ & 200 & 1 & 25 \\
\hline$P(7)$ & CS-100 & $0.05 \mathrm{M} \mathrm{HNO}_{3}$ & 200 & 1 & 25 \\
\hline$Q(7)$ & CS -100 & IN $\mathrm{HCOOH}$ & 200 & 1 & 25 \\
\hline$R(8)$ & BIB-DJ & $0.1 \mathrm{M} \mathrm{HNO}_{3}$ & 200 & 1 & 25 \\
\hline$S(8)$ & BIB-DJ & IN $\mathrm{HCOOH}$ & 200 & 1 & 25 \\
\hline$T(8)$ & BIB-DJ & $0.5 \underline{\mathrm{N}} \mathrm{HCOOH}$ & 200 & 1 & 25 \\
\hline
\end{tabular}




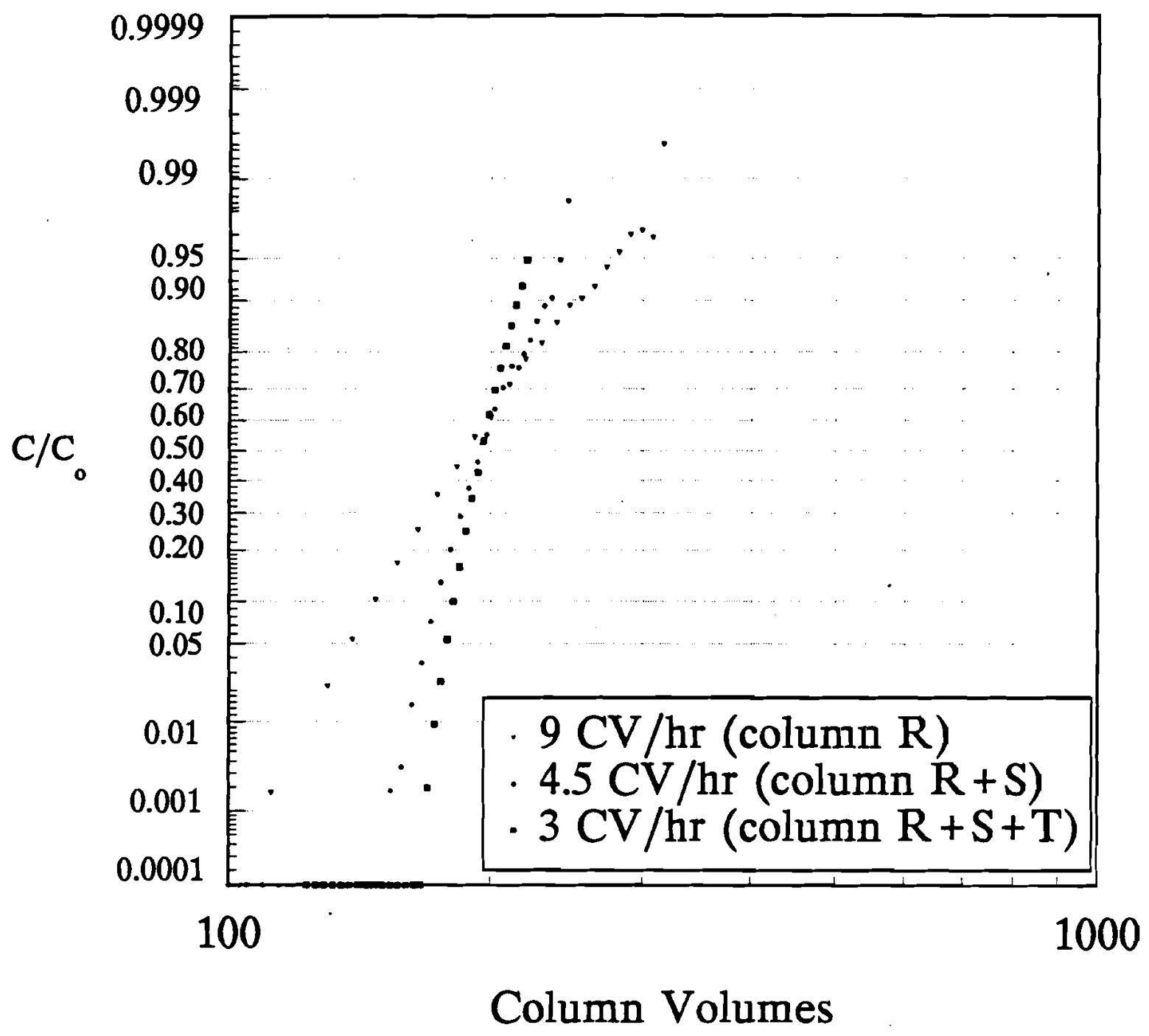

FIGURE 4.12. BIB-DJ Cesium Loading Results - Cs Breakthrough as a Function of Flow Rate 


\subsubsection{CS-100 Elution Tests}

Elution tests were initiated for CS-100 and ion exchange columns $0, P$, and $Q$ at $1 \mathrm{cv} / \mathrm{hr}$ and $25^{\circ} \mathrm{C}$ using nitric or formic acid, Figure 4.13 . The initial resin had been loaded to a value equal to the cesium contained in 30 column volumes of NCAW (Loading Test \#7). The $1 \mathrm{~N}$ HCOOH very efficiently eluted the cesium in $6 \mathrm{cv}$ of acid, concentrating the cesium 5-fold. However, the elution results for 0.05 (Figure 4.14) and $0.1 \mathrm{M} \mathrm{HNO}$ show that 5 to $12 \mathrm{cv}$ of dilute influent acid will pass through the column before the effluent was acidic as noted by the change in $\mathrm{pH}$. This is the result of the column containing residual hydroxide from the column post wash. This effect is not observed in the $1 \mathrm{~N} \mathrm{HCOOH}$ case because of the higher concentration of hydrogen ion, Figure 4.15. Discounting this potential recycle stream, the amount of 0.05 or $0.1 \mathrm{M}$ nitric acid required before reaching a $\mathrm{C} / \mathrm{Co}$ value of $\sim 0.001$ was $9 \mathrm{cr}$ and $13 \mathrm{cr}$ of acid respectively, concentrating the cesium 3 -fold.

When the above series of elution tests was repeated at a higher flow rate $\left(6 \mathrm{cv} / \mathrm{hr}\right.$ versus $1 \mathrm{cv} / \mathrm{hr}$ ), the volume of $1 \mathrm{~N} \mathrm{HCOOH}$ or $0.1 \mathrm{M} \mathrm{HNO}_{3}$ required to obtain the same elution efficiency doubled, Figure 4.16. The volume of the more dilute acid $\left(0.05 \mathrm{M} \mathrm{HNO}_{3}\right)$ did not change with flow rate.

When several tests were repeated at a higher temperature $\left(40^{\circ} \mathrm{C}\right.$ versus $\left.25^{\circ} \mathrm{C}\right)$ no change in acid requirement was observed, Figure 4.17.

\subsubsection{BIB-DJ Elution Tests}

Elution tests were initiated for BIB-DJ resin and ion exchange columns $R, S$, and $T$ at $1 \mathrm{cv} / \mathrm{hr}\left(25^{\circ} \mathrm{C}\right)$ using nitric or formic acid, Figure 4.18 . The double peak for the $\mathrm{HCOOH}$ elutions has not yet been identified. Analysis of the acid eluate may reveal that $\mathrm{K}, \mathrm{Rb}$, and $\mathrm{Na}$ are also being eluted in this region causing this observation. Each resin column had been loaded to a value equal to the cesium contained in $190 \mathrm{cv}$ of NCAW (Loading Test \#8). No acid tested removed the cesium down to a $C / C o$ level of 0.01 as was demonstrated for $\mathrm{CS}-100$, Figures 4.19 and 4.20. After passing $25 \mathrm{cv}$ of $0.1 \mathrm{M} \mathrm{HNO}_{3}$ through column R, 45\% of the cesium was eluted. After passing $31 \mathrm{cr}$ of either 0.5 or $1 \mathrm{M}$ HCOOH through Columns $T$ and $S, 97 \%$ of the cesium was eluted. Since $190 \mathrm{cv}$ of NCAW had originally been loaded on to the columns, even a $97 \%$ elution allows $5.7 \mathrm{cv}$ of cesium to remain on the resin. The relatively poor elution 
behavior of BIB-DJ may be due to the $35 \%$ volume shrinkage during elution when $\mathrm{Na}^{+}-\mathrm{K}^{+}-\mathrm{Cs}^{+}$is replaced with $\mathrm{H}^{+}$. There is a visible void space between the resin and the wall of the ion exchange column during elution. The tests were all carried out using downflow elution. It may be possible to improve the elution with upflow of the acid, such that the bed is fluidized, or by vibrating, the column to break up the resin. This may not be a problem in a larger column where the weight of the resin is much greater. These and other suggestions for improved elution characteristics will be evaluated in FY 94 . 


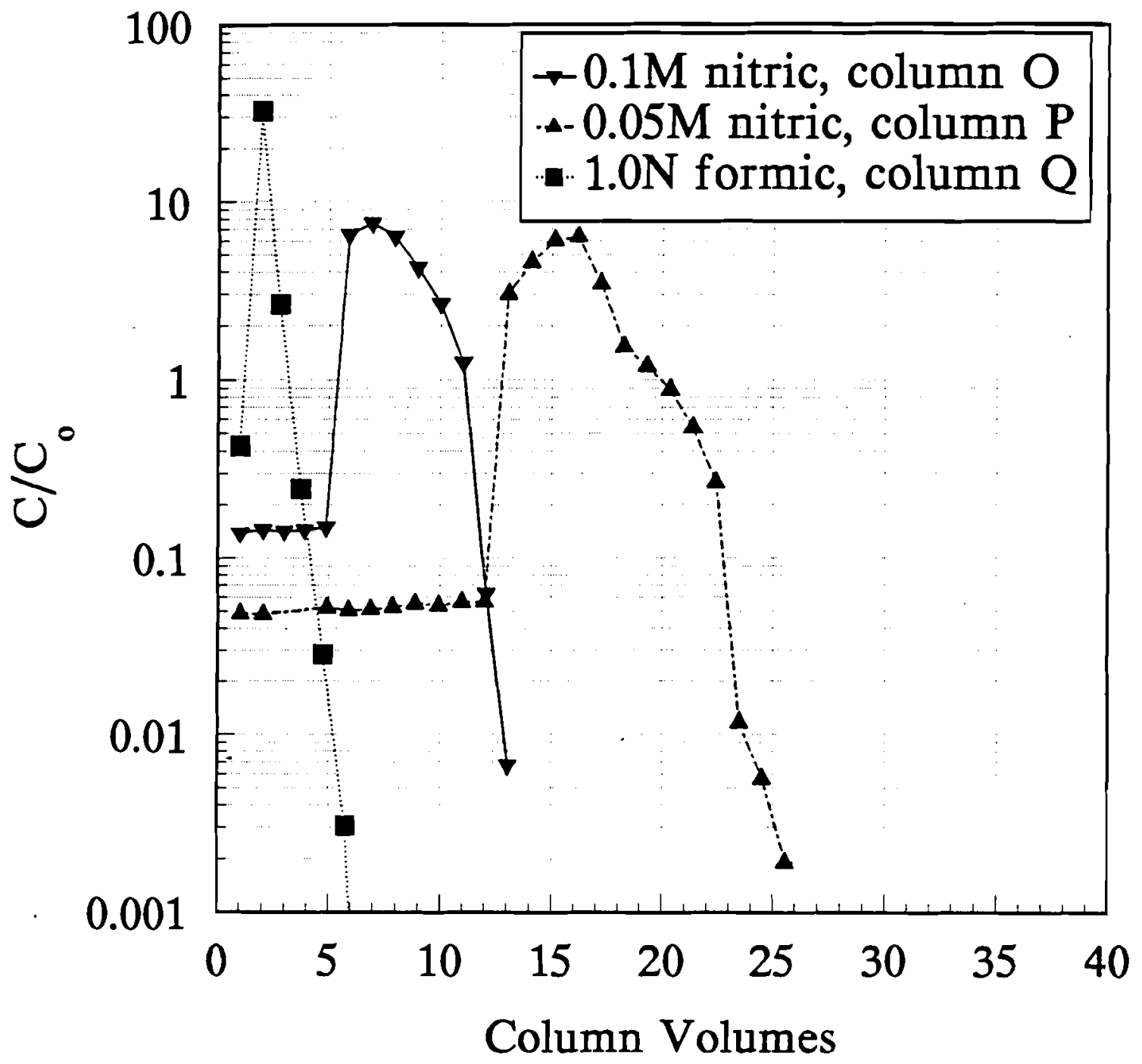

FIGURE 4.13. CS-100 Elution as a Function of Acid Concentration $-1 \mathrm{cv} / \mathrm{hr}, 25^{\circ} \mathrm{C}$ 


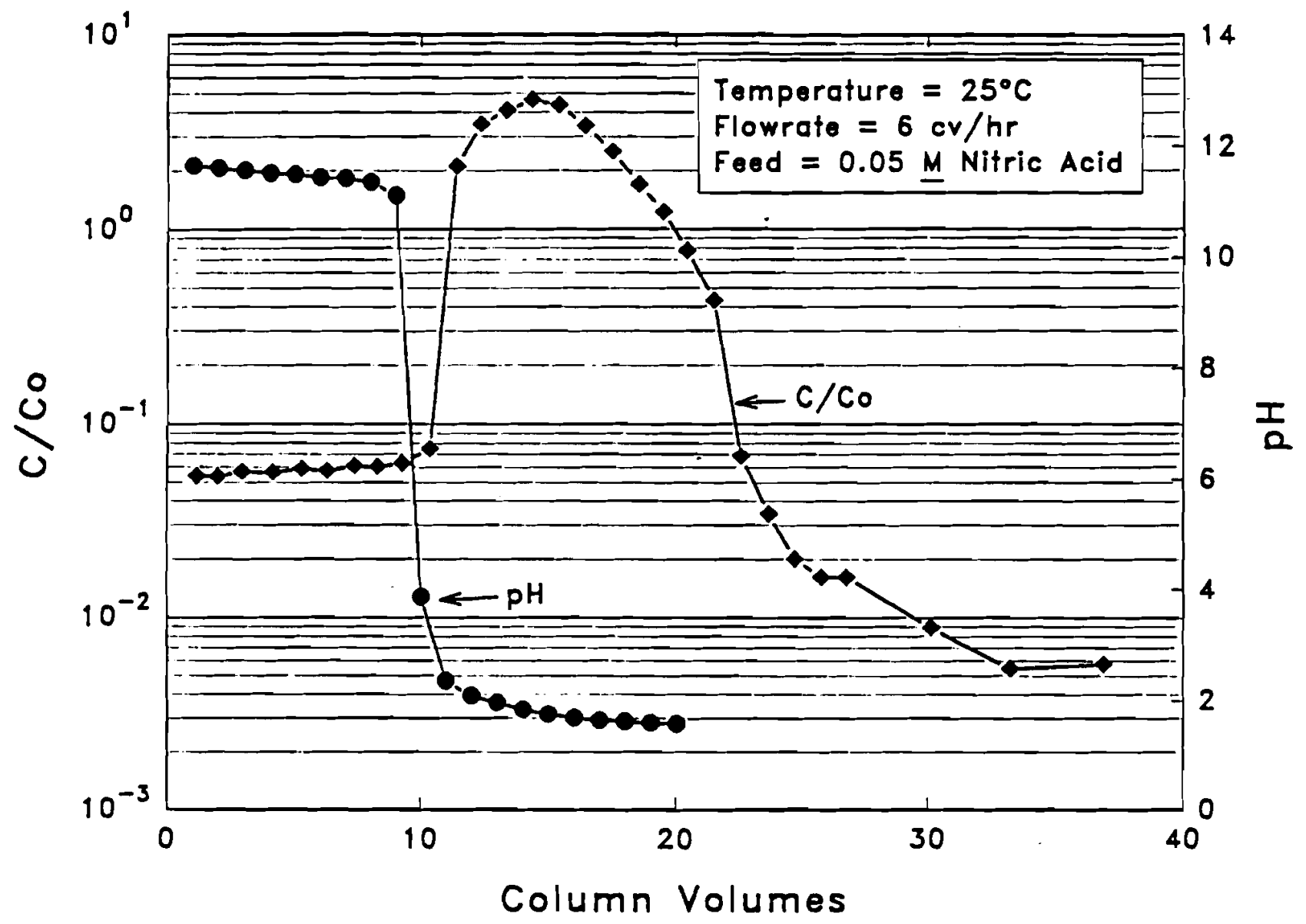

mance-mises os/00/83

Figure 4.14. $\mathrm{CS}-100$ Elution with $0.05 \mathrm{M} \mathrm{HNO}_{3}$ as a Function of $\mathrm{pH}$ 


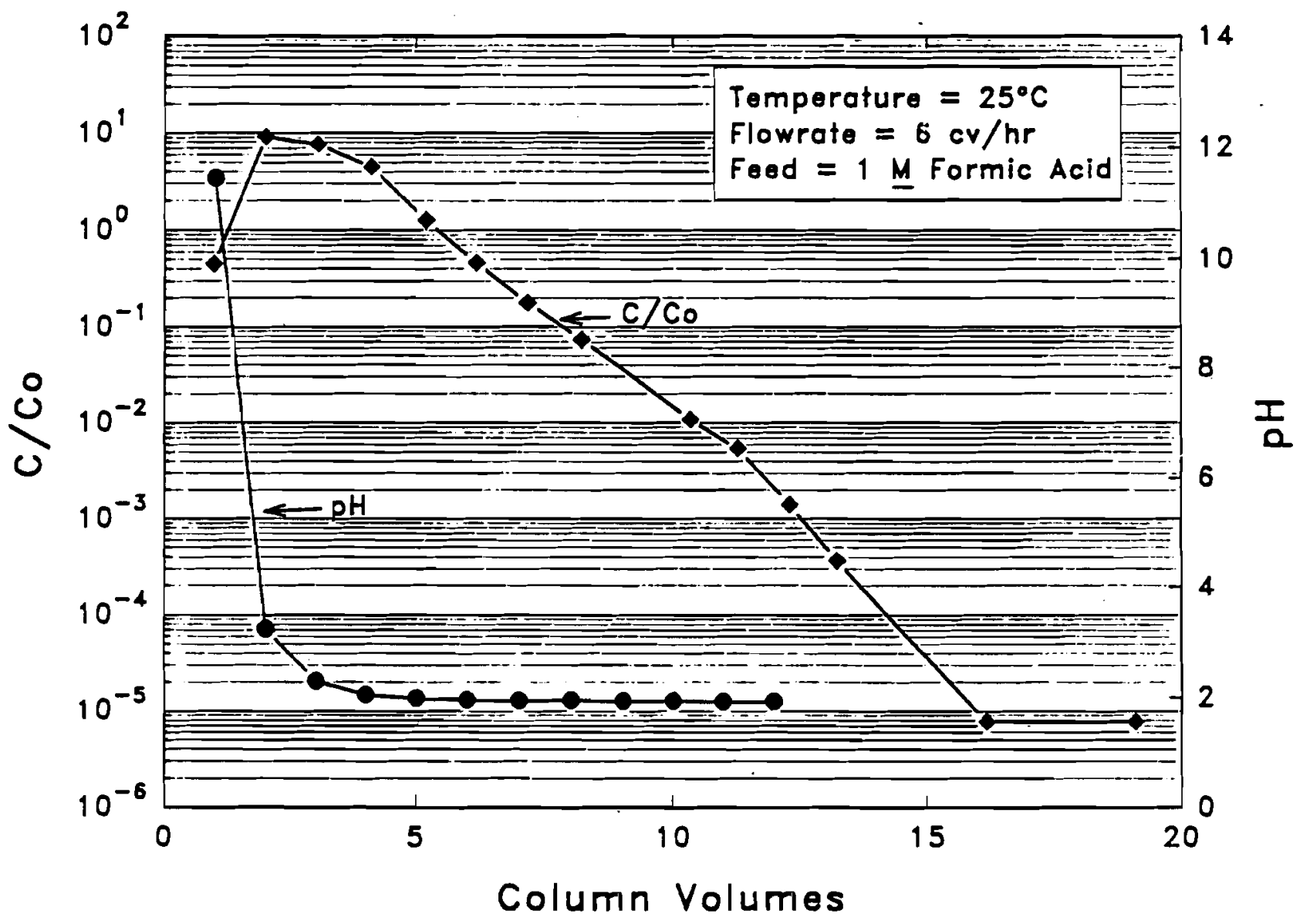

munce-m,ses 03/00/9s

Figure 4.15. CS-100 Elution with $1 \mathrm{M} \mathrm{HCOOH}$ as a Function of $\mathrm{pH}$ 


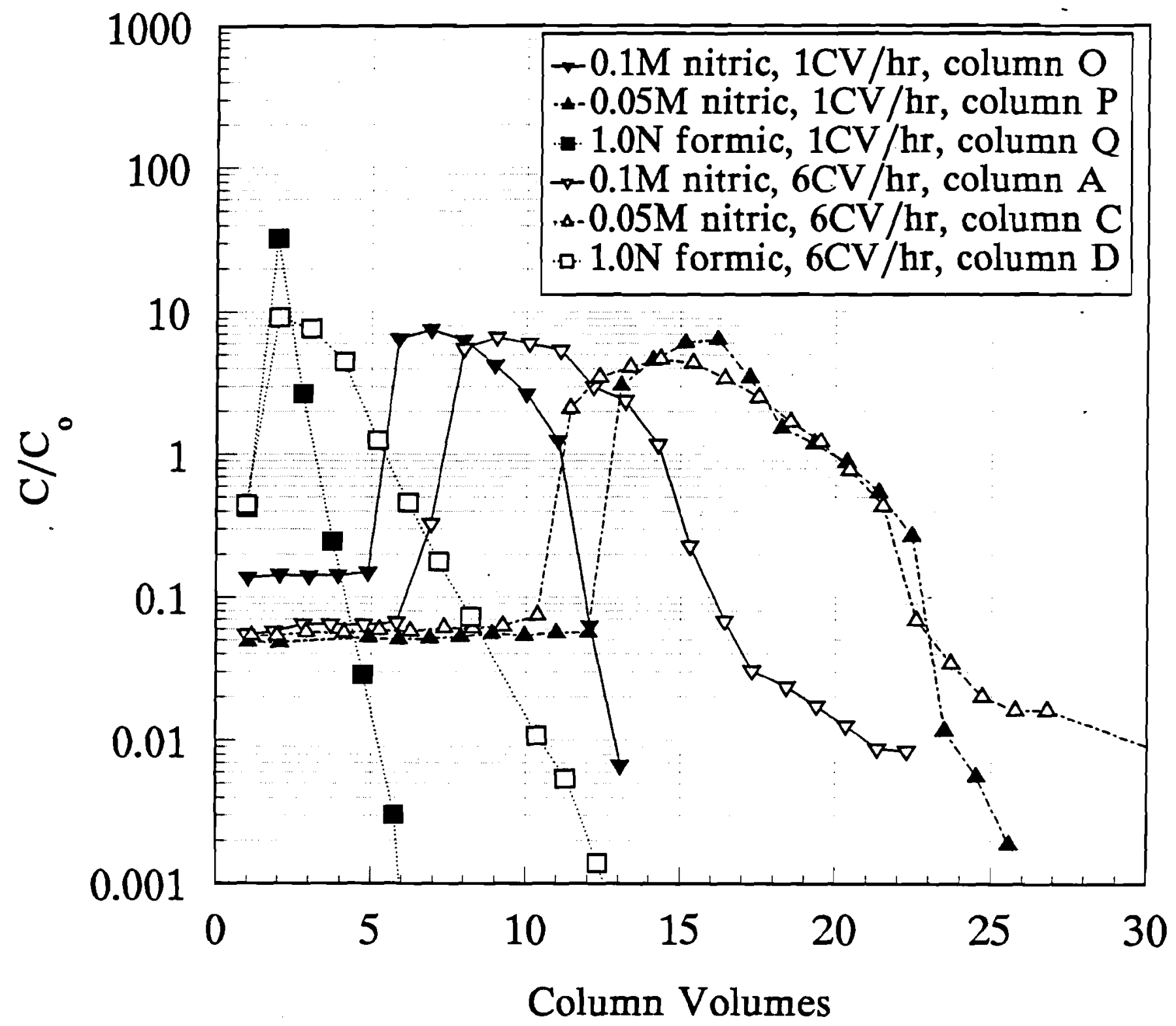

FIGURE 4.16. CS-100 Elution as a Function of Flow Rate - 1 to $6 \mathrm{cv} / \mathrm{hr}, 25^{\circ} \mathrm{C}$ 


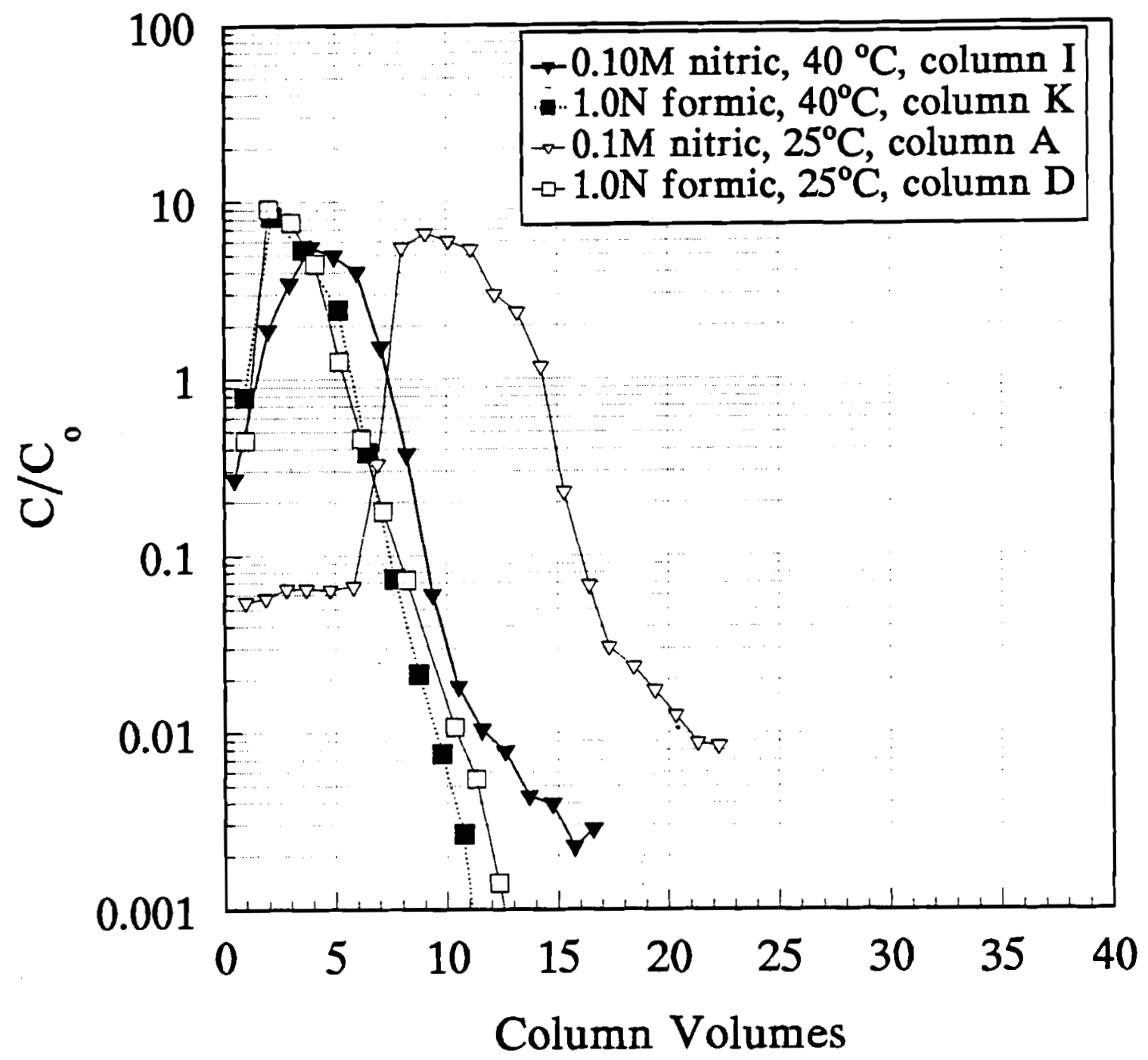

FIGURE 4.17 CS-100 Elution as a Function of Temperature $-6 \mathrm{cv} / \mathrm{hr}, 25^{\circ} \mathrm{C}-40^{\circ} \mathrm{C}$ 


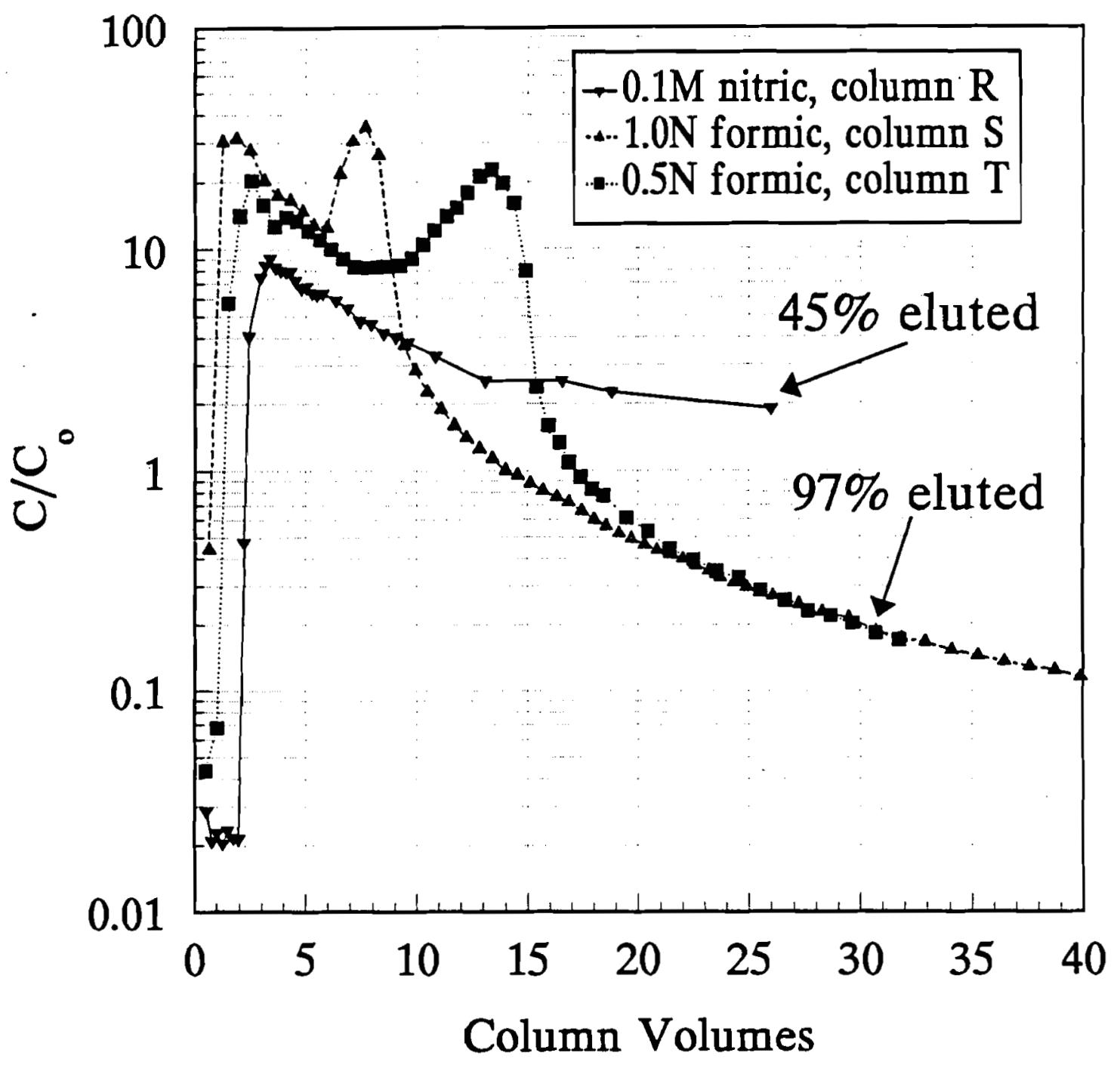

FIGURE 4.18. BIB-DJ Elution as a Function of Acid Concentration $-1 \mathrm{cv} / \mathrm{hr}, 25^{\circ} \mathrm{C}$ 


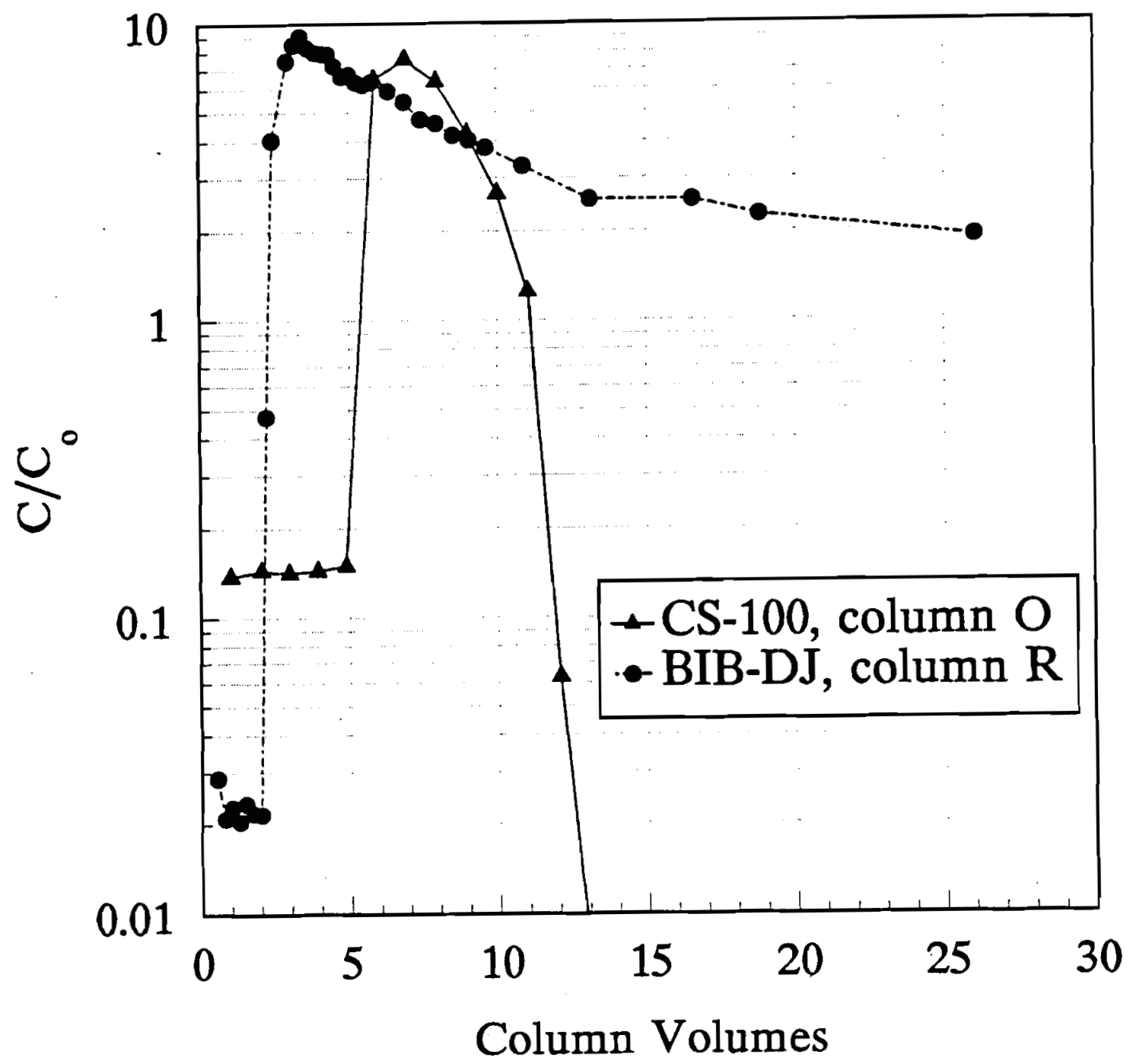

FIGURE 4.19. Elution of CS-100 and BIB-DJ Resins with $0.1 \mathrm{M} \mathrm{HNO}_{3}-1 \mathrm{cv} / \mathrm{hr}, 25^{\circ} \mathrm{C}$ 


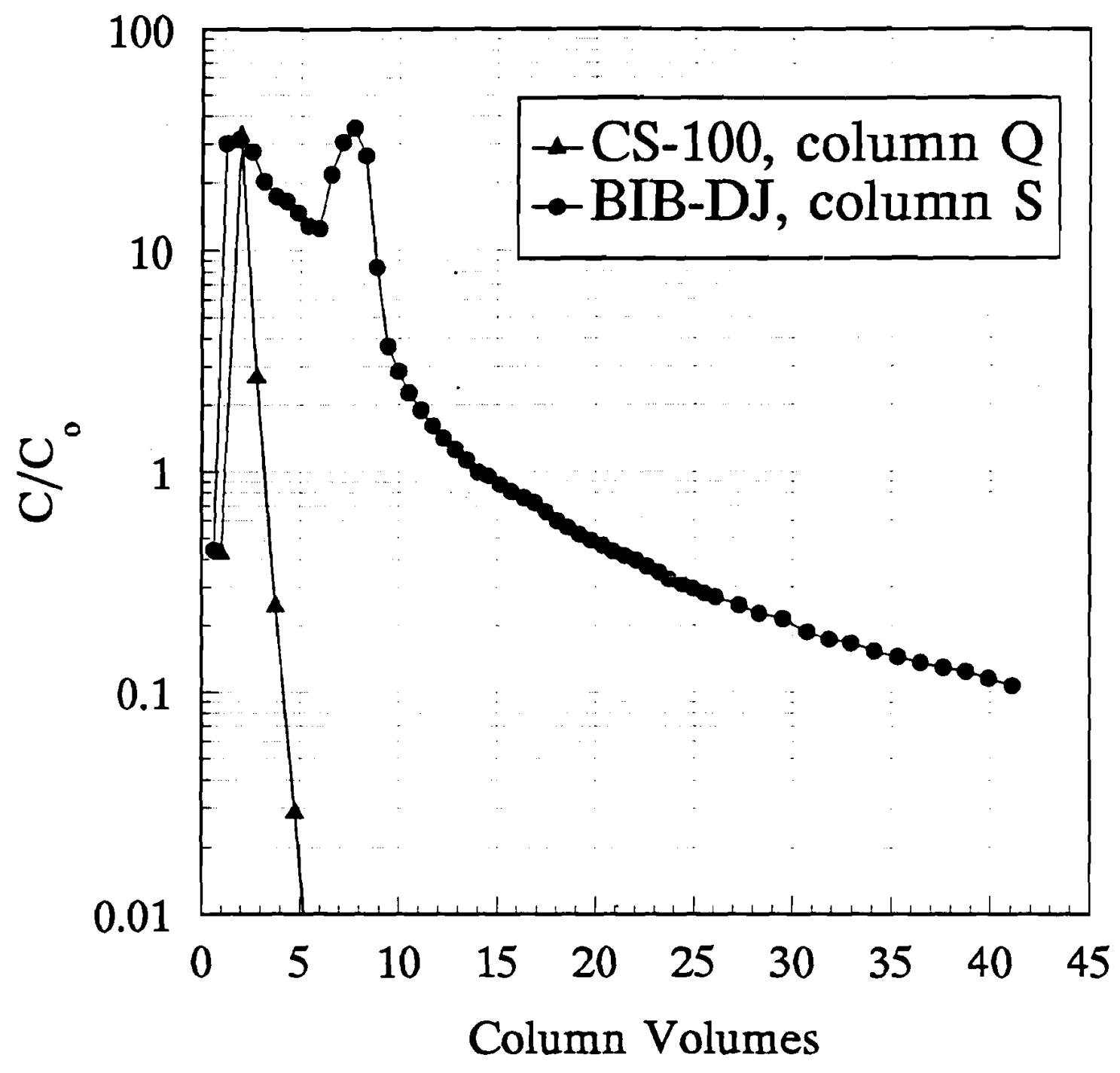

FIGURE 4.20. Elution of CS-100 and BIB-DJ Resins with IN Formic Acid $-1 \mathrm{cv} / \mathrm{hr}, 25^{\circ} \mathrm{C}$ 


\subsection{FUTURE STUDIES}

Future work will center on the resorcinol-formaldehyde resin (BIB-DJ). Loading and elution studies will be continued to evaluate the current resin and new commercial resin being manufactured by Boulder Scientific Co (ordered for delivery 9/93). In addition, engineering evaluation of the data to provide a scale-up model will be completed. Radiation damage is currently being studied and will be reported. Other types of waste and conditions will be evaluated in FY 94 . 


\subsection{REFERENCES}

Bray, L. A., K. J. Carson and R. J. Elovich. 1993. Initial Evaluation of Sandia National Laboratory Prepared Crystalline Silico-Titanates for the Recovery of Cesium, TWRSPP-93-013, prepared for Westinghouse Hanford Co; Pacific Northwest Laboratory, Richland, WA.

Bray, L. A. , K. J. Carson, R. J. Elovich, and D. E. Kurath. 1992. Equilibrium Data for Cesium Ion Exchange of Hanford CC and NCAW Tank Waste, TWRSPP-92-020, Pacific Northwest Laboratory, Richland, Washington.

Bray, L. A., K. J. Carson, R. J. Elovich, and D. E. Eakin. 1991a. HWVP Transuranic Waste Treatment by Ion Exchange at High PH, PHTD-C91-03.06C, Pacific Northwest Laboratory, Richland, Washington.

Bray, L. A. and F. T. Hara. 1991b. Use of Titanium Treated Zeolite for Pu, Sr and CS Removal from West Valley ATkaline Wastes and Sludge Washes, PNL-SA$19697 S_{1}$ (Invited), First Hanford Separations Science Workshop, July 23-25, 1991, Pacific Northwest Laboratory, Richland, WA.

Bray, L. A., K. J. Carson, R. J. Elovich, and D. E. Eakin. 1990a. HWVP Transuranic Process Waste Treatment by Ion Exchange, HWVP-90-1.2.2.04.04A, Pacific Northwest Laboratory, Richland, Washington.

Bray, L. A., K. J. Carson, and R. J. Elovich. 1990b. Cesium Recovery Using Savannah River Laboratory Resorcinol-Formaldehyde Ion Exchange Resin, PNL7273, Pacific Northwest Laboratory, Richland, Washington.

Bray, L. A. 1989a. PNL Test Procedure, "Determination of Batch Sorption Ratios for Ion Exchange Materials Using Radionuclide Tracer Techniques," WTC-006-21-1.

Bray, L. A. 1989b. Studies of Technology for the In-Tank Removal of Cesium/Strontium from Double Shell Tank Feeds. Milestone letter report for the Westinghouse Hanford Company.

Bibler, J. P. (SRL), R. M. Wallace (SRL), and L. A. Bray. 1989c. Testing A New Cesium-Specific Ion Exchange Res in For Decontamination of Alkaline-High Activity Waste. For presentation at the 1990 Waste Management Meeting, Tucson, Arizona, February 25 - March 1, 1990.

Kurath, D. E., L. A. Bray, W. A. Ross, and D. K. Ploetz (WVNS). 1989d. Correlation of Laboratory Testing and Actual Operations for the West Valley Supernatant Treatment System, PNL-SA-16871. Presented at the Fourth International Symposium on Ceramics in Nuclear Waste Management, American Ceramic Society Annual Meeting, April 23-27, 1989.

Bray, L. A., L. K. Holton, T. R. Myers, G. M. Richardson, and B. M. Wise. 1984. Experimental Data Developed to Support the Selection of a Treatment Process for West Valley Alkaline Supernatant. PNL-4969, Pacific Northwest Laboratory, Richland, Washington. 